OPEN ACCESS

Edited by:

Sheri Mizumori,

University of Washington,

United States

Reviewed by:

Serge H. Ahmed,

Centre National de la Recherche

Scientifique (CNRS), France

Kevin Coffey,

University of Washington,

United States

*Correspondence:

Katherine M. Nautiyal

katherine.nautiyal@dartmouth.edu

Specialty section:

This article was submitted to

Learning and Memory,

a section of the journal

Frontiers in Behavioral Neuroscience

Received: 08 October 2021

Accepted: 11 January 2022

Published: 17 February 2022

Citation:

Desrochers SS, Spring MG and Nautiyal KM (2022) A Role for Serotonin in Modulating Opposing Drive and Brake Circuits of Impulsivity. Front. Behav. Neurosci. 16:791749.

doi: 10.3389/fnbeh.2022.791749

\section{A Role for Serotonin in Modulating Opposing Drive and Brake Circuits of Impulsivity}

\author{
Stephanie S. Desrochers, Mitchell G. Spring and Katherine M. Nautiyal* \\ Department of Psychological and Brain Sciences, Dartmouth College, Hanover, NH, United States
}

Impulsivity generally refers to a deficit in inhibition, with a focus on understanding the neural circuits which constitute the "brake" on actions and gratification. It is likely that increased impulsivity can arise not only from reduced inhibition, but also from a heightened or exaggerated excitatory "drive." For example, an action which has more vigor, or is fueled by either increased incentive salience or a stronger actionoutcome association, may be harder to inhibit. From this perspective, this review focuses on impulse control as a competition over behavioral output between an initially learned response-reward outcome association, and a subsequently acquired opposing inhibitory association. Our goal is to present a synthesis of research from humans and animal models that supports this dual-systems approach to understanding the behavioral and neural substrates that contribute to impulsivity, with a focus on the neuromodulatory role of serotonin. We review evidence for the role of serotonin signaling in mediating the balance of the "drive" and "brake" circuits. Additionally, we consider parallels of these competing instrumental systems in impulsivity within classical conditioning processes (e.g., extinction) in order to point us to potential behavioral and neural mechanisms that may modulate the competing instrumental associations. Finally, we consider how the balance of these competing associations might contribute to, or be extracted from, our experimental assessments of impulsivity. A careful understanding of the underlying behavioral and circuit level contributions to impulsivity is important for understanding the pathogenesis of increased impulsivity present in a number of psychiatric disorders. Pathological levels of impulsivity in such disorders are likely subserved by deficits in the balance of motivational and inhibitory processes.

Keywords: serotonin, impulsivity, reward, inhibition, learning

\section{INTRODUCTION}

Impulsivity is generally conceived of as a deficit in inhibitory control, resulting in unwanted actions. However, impulsive behavior has many diverse presentations and complex neurobiological underpinnings (Dalley and Robbins, 2017; Strickland and Johnson, 2021). Many lines of work have fractionated impulsivity into a number of different subtypes and components, with dissociable 
biological bases (Winstanley et al., 2004; Robbins et al., 2012; Bari and Robbins, 2013; MacKillop et al., 2016; Dalley and Robbins, 2017; Nautiyal et al., 2017; Bailey et al., 2021). Impulsive choice is described as risky decision making, including discounting of delayed rewards. Alternatively, impulsive action is characterized by acting prematurely and/or the decreased ability to stop or withhold responding. In this review, we focus on the action component of impulsivity, exploring the idea that impulse control can be broadly described as competing circuits. One "drive" circuit encodes an initially learned response-reward outcome association, and the second "brake" circuit subserves an opposing and subsequently learned inhibitory association. The sum of the outputs of these circuits shapes the action plan determining whether to go or inhibit going. In particular, we highlight the role of serotonin signaling in modulating these oppositional circuits in the control of impulsive action.

Dysfunction in different nodes of these "drive" and "brake" neural circuits could result in the heterogeneity of phenotypic presentations of impulsivity. Therefore, careful dissection of the underlying behavioral and circuit level contributions to impulsivity is important for understanding the pathogenesis of increased impulsivity. This idea is highlighted in the dual systems and imbalance models of adolescent impulsivity which consider disproportionate development and changes in communication for brain areas involved in reward/motivation and inhibitory control (Somerville et al., 2010; Steinberg, 2010; Casey et al., 2011; Ellingson et al., 2013). Considering imbalance models in the context of preclinical studies aimed at understanding adult impulsivity could help elucidate different entry points to dysfunctional circuits responsible for pathological impulsivity.

This dual-systems perspective is also relevant to clinical populations with disorders in which impulsivity is dysregulated. For example, attention deficit hyperactivity disorder (ADHD) is characterized by inhibitory deficits, including increased impulsive action (Schachar and Logan, 1990; Nigg, 2001; Wright et al., 2014; Grandjean et al., 2021). Impulsivity is also a key phenotype found in substance use disorder, in which both reward system and inhibitory dysfunctions are present (Jentsch et al., 2014; Weafer et al., 2014). From the perspective of reward sensitivity, genetic risk for alcoholism is associated with increased sensitivity to sweet substances (Kampov-Polevoy et al., 2001, 2003). Poor inhibitory control is associated with sensitivity to amphetamines (Weafer and De Wit, 2013; Weafer et al., 2017) and chronic cocaine use (Fillmore and Rush, 2002). Increased impulsive action likely reduces the ability to withhold actions to obtain or consume drugs, though it is difficult to parse out the cause versus effect, as is common generally when studying psychiatric disorders. However, it is clear that impulsivity is both a predisposing factor and a result of drug use. Several studies which supports a role for impulsivity as a causal factor shows that subjects with familial history of drug dependence have higher impulsivity across many domains, including impulsive action (Acheson et al., 2011; Ersche et al., 2012; Kumar et al., 2018). Additionally, increased impulsivity and altered reward sensitivity are also found in gambling disorder (Sztainert et al., 2013; Hodgins and Holub, 2015; Wardell et al.,
2015; Jiménez-Murcia et al., 2017; Ioannidis et al., 2019; MestreBach et al., 2020), which, as a behavioral addiction, is free from the confound of pharmacological effects on these phenotypes. Indeed, Brevers et al. (2012) found that the severity of problem gambling was predicted by performance on a stop-signal test of impulsive action.

Assuming the presence of competing drive and brake processes in impulsivity, we can examine the behavioral/cognitive components and the underlying neural mechanisms of each of these components. This sets up the possibility to arrive at the endpoint of increased impulsive behavior via a number of different paths and combinations of intermediate phenotypes (Figure 1). For example, in a behavioral assay of impulsive action, increased maladaptive actions could arise from a stronger action-outcome association, an increased motivation or valuation of reward, a failure to learn the opposing behavioral response (inhibition), or even a failure to express the inhibition, despite it having been learned. Understanding which components contribute to impulsive phenotypes, can lead toward developing novel, specific treatments targeting dysfunction of neural circuitry more precisely.

Serotonin (5-HT) has been strongly implicated in encoding reward and mediating behavioral inhibition, and is poised to modulate the balance of reward-based approach and adaptive inhibition of action. Manipulation of serotonin neuron activity in preclinical models clearly show that serotonin is involved in waiting and inhibiting behavioral responses (Wogar et al., 1992; Fletcher, 1995; Jolly et al., 1999; Winstanley et al., 2004; Fonseca et al., 2015; Miyazaki et al., 2018, 2020). Studies using in vivo monitoring, through single-unit electrophysiology and photometric calcium monitoring, in the dorsal raphe also implicate serotonin neurons in encoding both rewards and associated cues (Cohen et al., 2015; Li et al., 2016; Zhong et al., 2017; Ren et al., 2019). A large number of studies have also investigated the role of serotonin signaling-through many of its 14 receptors-in both reward-related behaviors and behavioral inhibition. Though many have used pharmacological approaches with systemically administered drugs, some studies have targeted brain region specificity with local drug administration and celland circuit-specificity using genetic models (Table 1). Given that serotonin, as a neuromodulator, tunes synaptic signaling and guides plasticity to alter learning and motivated behaviors, it is relevant to explore the idea that serotonin acts at the convergence of the neural circuits governing "drive" and "brake" processes in impulsivity.

The first goal of this review is to synthesize studies, especially in preclinical animal models, that parse excitatory and inhibitory behavioral substrates that contribute to impulsive action. Next, we review potential circuit level mechanisms that underlie the interaction of these opposing learned associations in the generation of impulsivity. We focus on serotoninergic modulation of the underlying neural circuitry of both reward processing and inhibitory control, and also potentially in determining the balance of these competing systems to generate the output impulsive behavior. Finally, we discuss future research questions which examine the relative contributions of initial response-reward associations and subsequently learned 


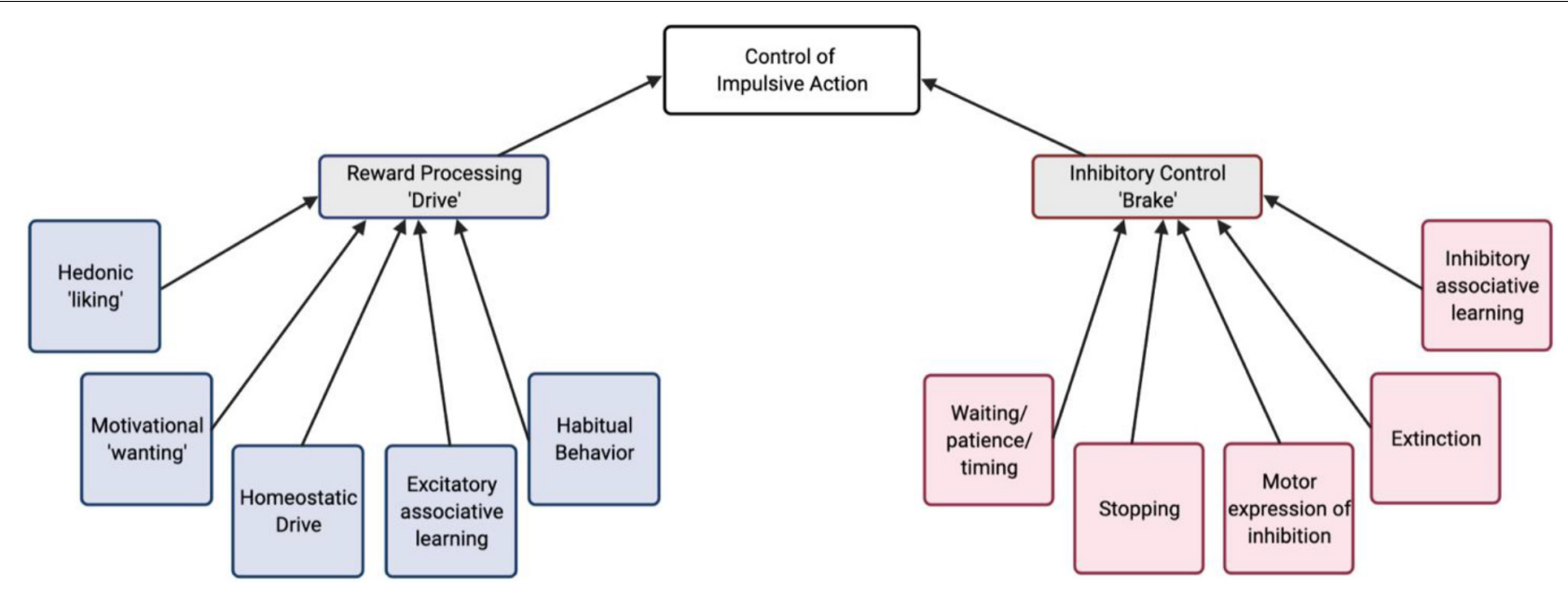

FIGURE 1 | A conceptual schematic of behavioral/cognitive processes that contribute to the control of impulsive action. These are organized into reward "drive" and inhibitory "brake" processes.

TABLE 1 | Effects of serotonin receptors on reward-related and impulsive action behavior from preclinical pharmacology and genetic mouse models.

\begin{tabular}{|c|c|c|c|}
\hline Receptor & Behavioral effects & Reward & Behavioral inhibition: impulsive action \\
\hline $5-\mathrm{HT}_{2 \mathrm{~A}}$ & $\begin{array}{l}\text { Pro-hallucinogenic, necessary for } \\
\text { psychedelic effects }\end{array}$ & Activation decreases incentive motivation ${ }^{12,13}$ & $\begin{array}{l}\text { Activation increases impulsive action, antagonists reduce } \\
\text { impulsivity }{ }^{14-17}\end{array}$ \\
\hline $5-\mathrm{HT}_{2 \mathrm{C}}$ & $\begin{array}{l}\text { Influences feeding, stress, and sex } \\
\text { behavior }\end{array}$ & Activation reduces incentive motivation ${ }^{13}$ & Activation decreases impulsive action ${ }^{15,17}$ \\
\hline $5-\mathrm{HT}_{3}$ & Nausea & $\begin{array}{l}\text { Limited direct effects, but is necessary for the } \\
\text { rewarding effects of MDMA, cocaine, morphine, } \\
\text { and ethanol }{ }^{12,20-25}\end{array}$ & No established effects \\
\hline $5-\mathrm{HT}_{4}$ & Anxiety, depression, and feeding & No effect ${ }^{26}$ & No established effects \\
\hline
\end{tabular}

Blue and orange shading represent directionality (decreased or increased, respectively) of receptor activation effects on reward-related behaviors and impulsive action. ${ }^{1}$ Balleine et al. (1996), ${ }^{2}$ Fletcher et al. (1993), ${ }^{3}$ Fletcher et al. (1995), ${ }^{4}$ Groft et al. (2019), ${ }^{5}$ Miyazaki et al. (2012), 6 Korte et al. (2017), ${ }^{7}$ Harrison et al. (1999b), ${ }^{8}$ Desrochers et al. (2021), ${ }^{9}$ Acosta et al. (2005), ${ }^{10}$ Fletcher et al. (2002), ${ }^{11}$ Pattij et al. (2003), ${ }^{12}$ Frick et al. (2015), ${ }^{13}$ Fletcher et al. (2017), ${ }^{14}$ Koskinen et al. (2000a), ${ }^{15}$ Silveira et al. (2020), ${ }^{16}$ Talpos et al. (2006), ${ }^{17}$ Fletcher et al. (2007), ${ }^{18}$ Doly et al. (2009), ${ }^{19}$ Goldman et al. (2010), ${ }^{20}$ Fletcher and Higgins (1997), ${ }^{21}$ Roger-Sánchez et al. (2013), ${ }^{22}$ Kelley and Hodge (2003), ${ }^{23}$ Rodd-Henricks et al. (2003), ${ }^{24}$ Rompré et al. (1995), ${ }^{25}$ Higgins et al. (1992), ${ }^{26}$ Reavill et al. (1998), ${ }^{27}$ Mitchell et al. (2007), ${ }^{28}$ Brodsky et al. (2016), ${ }^{29}$ Ferguson et al. (2008), ${ }^{30}$ Valentini et al. (2013), ${ }^{31}$ da Silva et al. (2018), and ${ }^{32}$ de Bruin et al. (2013).

inhibitory associations to increased impulsivity in terms of both behavioral substrates and the underlying neural circuits.

\section{THE DRIVE: CONTRIBUTIONS OF REWARD PROCESSING TO IMPULSIVITY}

Impulsivity is innately tied to reward processing, with excitatory drive being a key aspect of motivated behavior. Importantly, before being able to consider an inhibitory process, a motivated behavior needs to exist. This commonly includes a learned cue-reward or action-outcome association. In other words, we first learn to respond to obtain rewarding outcomes, prior to learning to avoid responding in certain circumstances (an innate or learned propensity to "go"). Alterations in appetitive associations may change the strength of the drive for reward. This could include differences in the intrinsic value/pleasurability of a reward (liking), and/or changes in the motivational value of the reward/reward paired cues (wanting). Though these are experimentally separable (Peciña, 2008; Berridge and Robinson, 2016; Morales and Berridge, 2020), they are linked together 
such that changes to either "liking" or "wanting" would likely increase actions in pursuit of reward, a characteristic of impulsive action. Therefore, superficially similar clinical presentations could actually be the result of dysfunction in different underlying neural mechanisms. Careful behavioral analysis using a variety of tests in different reward domains may allow us to identify the mechanisms contributing to pathological levels of impulsivity.

\section{Reward Processing in Classical Conditioning}

Though impulsivity is defined in terms of operant behavior, in which impulsive behavior is characterized by actions that have unwanted consequences, the processes that underlie impulsive behavior may also be measurable at the level of Pavlovian tasks if they include changes to reward processing. In other words, if an instance of increased impulsivity was due to a change in the drive process, it may be able to be seen in altered appetitive classical conditioning, when outcomes are independent of action. For example, changes to the magnitude/value of an unconditioned stimulus influences the associative strength of conditioned cues, resulting in enhanced conditioned responding (Rescorla and Wagner, 1972; Pearce and Hall, 1980; Van Den Bos et al., 2004; Morris and Bouton, 2006). For appetitive conditioning, increased reward value due to altered hedonic pleasure or homeostatic processes could therefore increase the salience or associative strength of a cue, such that vigor of responding correlates with the perceived magnitude. If the value of a reward was subjectively increased, either due to pathological neural changes or simply everyday variations in reward preference in non-pathological cases, we would expect that subjects would form a stronger association between the cue and the reward and therefore have generally increased responding. For example, the phenomenon of signtracking, where animals may interact with a manipulable cue as if it were the reward which it has come to be associated with, shows that a classically conditioned cue can acquire increased incentive salience (Flagel et al., 2011). In fact, rats bred for a high novelty responding phenotype had increased signtracking behaviors along with a decreased ability to withhold responding in the differential reinforcement of low-rate responding test of impulsive action (Flagel et al., 2010). This interestingly correlates incentive salience with impulsivity - either subserved by a single underlying endophenotype or possibly due to a causal link of increased incentive salience leading to increased impulsive action. Interestingly high novelty responding rats also increased preference for the large reward in a delay discounting test of impulsive choice. Overall this study supports the idea that increased reward sensitivity may underlie both the operant impulsive and Pavlovian signtracking phenotypes. Additionally, in a study of excitatory Pavlovian responding during the adolescent developmental period, which is often characterized by heightened reward reactivity and impulsivity, adolescents showed increased responding under partial reinforcement conditions compared to adults (Meyer and Bucci, 2016a). This suggests that developmentally mediated impulsivity and altered classical conditioning may be modulated by similar reward-based changes. Taken together, the consideration of the processes which contribute to responding in appetitive classical conditioning may shed light on the mechanisms through which reward processing contributes to impulsive behavior.

Multiple neural substrates have been implicated in assigning value to an outcome or cue and incentive motivation. Dysregulation of any number of highly interconnected implicated brain regions could therefore result in altered reward related behavior. Several regions appear to represent or integrate reward value, including the nucleus accumbens (NAc), ventral pallidum (VP), basolateral amygdala (BLA), and regions of the prefrontal cortex including the orbitofrontal cortex (OFC) (Amiez et al., 2006; Chen et al., 2015; Howard et al., 2015; Wassum and Izquierdo, 2015; Ottenheimer et al., 2018). In particular, distinct areas of both the NAc (Peciña and Berridge, 2005; Peciña, 2008; Castro and Berridge, 2014) and the VP (Tindell et al., 2006; Ahrens et al., 2016; Richard et al., 2016; Smith et al., 2009) have been implicated in hedonic "liking" of reward assessed through taste reactivity, as well as incentive motivation "wanting." The NAc is poised to integrate cortical and limbic information about reward and output to the VP, the subthalamic nucleus (STN), the substantia nigra, the ventral tegmental area (VTA), and the lateral hypothalamus, providing a mechanism for translating value assessment and motivation into behavior (Mogenson et al., 1983; Robbins and Everitt, 1996). Indeed, as reviewed by Day and Carelli (2007), the NAc and its connections are critical to appetitive Pavlovian cue-outcome learning, both in association acquisition and motoric expression. In sum, changes in brain regions involved in both "liking" and "wanting" aspects of reward processing could contribute to increased responding to conditioned stimuli during appetitive classical conditioning by subjectively increasing the outcome value.

\section{Contributions of Serotonin to Classical Conditioning Through Modulation of Reward Processing}

Many brain regions involved in reward encoding and classical conditioning are innervated by the serotonin system, rendering serotonin as a well-positioned modulator of reward processes (Huang et al., 2019; Ren et al., 2019; Figure 2A). Serotonergic neurons within the dorsal raphe nucleus (DRN) respond by increasing firing to both expected and unexpected rewards (Cohen et al., 2015; Li et al., 2016; Zhong et al., 2017), indicating that serotonin generally does not encode "surprise" or predictionerror. Rather, during classical conditioning, some DRN neurons develop a ramping response to reward-predictive cues, with response magnitude being commensurate to expected reward value (Nakamura et al., 2008; Bromberg-Martin et al., 2010). This response specifically requires that stimuli have acquired value through conditioning (Zhong et al., 2017), and differs from the response of other DRN neurons during aversive experiences (Hayashi et al., 2015). Thus, serotonergic signaling reflects the value (either learned, in the case of cues, or innate, in the case of rewards or punishments) of stimuli, with different populations (and projections; Ren et al., 2018) responding selectively to appetitive or aversive events.

Serotonin's involvement in reward processes ultimately depends on not only the activity of serotonergic neurons, but also the projection targets as well as the receptors expressed in 


\section{A Reward}

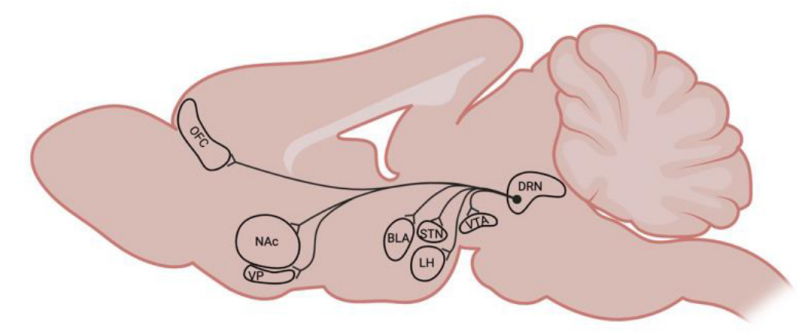

\section{B Inhibition}

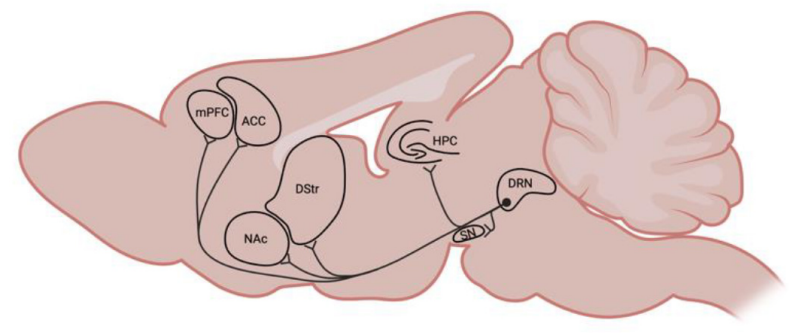

FIGURE 2 | A simplified schematic of rodent Dorsal Raphé serotonergic efferents to brain regions implicated in reward (A) or behavioral inhibition (B). ACC, anterior cingulate cortex; BLA, basolateral amygdala; DRN, dorsal raphé nucleus; DS, dorsal striatum; HPC, hippocampus; LH, lateral hypothalamus; mPFC, medial prefrontal cortex; NAc, nucleus accumbens; OFC, orbitofrontal cortex; STN, subthalamic nucleus; SN, substantia Nigra; VP, ventral pallidum; VTA, ventral tegmental area.

those areas. Brain regions within canonical reward circuitryand containing "hedonic hotspots" (Peciña et al., 2006)-receive dense innervation from the DRN and express various serotonin receptors. Serotonin signaling in some of these reward processing regions, specifically the NAc and VP, appears to mediate the euphoric effects of recreational drugs (Yoshimoto et al., 1992, 2012; Napier and Istre, 2008; Matsui and Alvarez, 2018). However, the hedonic effects of serotonin signaling are not consistent across all receptors, and specifically targeting distinct receptors manifests varied, and sometimes opposite, effects (Table 1). Manipulating general serotonin tone via systemic agonism of $5-\mathrm{HT}_{1 \mathrm{~A}}$ receptors (thought to increase synaptic serotonin by antagonizing autoreceptors) or genetic knockout of serotonin transporters (SERT; also thought to generally increase synaptic serotonin, Homberg et al., 2007) fails to alter hedonic liking of palatable tastes (Treit and Berridge, 1990; Caras et al., 2008) or incentive wanting for reward paired cues (Nonkes et al., 2014). However, subjects with depleted serotonin levels display reduced neural responsivity to rewards in fMRI (Seymour et al., 2012), and we recently demonstrated that mice lacking the $5-\mathrm{HT}_{1 \mathrm{~B}}$ receptor seem to have increased subjective reward valuation, including enhanced hedonic taste reactivity to sucrose in a lickometer test (Desrochers et al., 2021). Taken in totality, this evidence suggests that serotonin likely does not have a unified brain-wide role in reward processing. Rather, to accurately characterize serotonin's functions, region, cell-type, and receptor specificity must be considered.

Communication between subregions of the OFC and BLA is crucial in learning, representing, and using the value of cues to guide behavior (Malvaez et al., 2019; Lichtenberg et al., 2021; Sias et al., 2021), and serotonergic signaling regulates this communication. Serotonin neurons projecting to the BLA respond to both reward and punishment (Ren et al., 2018) and may have a general role in tuning the response of this region to stimuli; BLA serotonin activates GABAergic interneurons, which inhibit excitatory projection neurons (Rainnie, 1999; Bocchio et al., 2015), and should be expected to mute the area's response to salient stimuli. Interestingly, the dampening effect on BLA activity appears to depend on balanced serotonin signaling; while acute administration of serotonin excites inhibitory interneurons, prolonged exposure to serotonin (such as would occur in the absence of proper serotonin re-uptake) reduces the inhibitory output of interneurons on BLA principal neurons (Rainnie, 1999). In agreement with this, reduced 5-HT levels following excitotoxic lesion or 5-HT desensitization, leads to amygdalar over-activity and over-responding to reward paired cues (Nonkes et al., 2010; Man et al., 2012). Serotonin in the OFC regulates anticipatory encoding of reward in response to predictive cues (Zhou et al., 2015) and coordinates emotional and behavioral responses to those cues (Man et al., 2012). Overall changes to serotonin signaling in these areas results in deficits in the ability to represent and use expected outcome values and increases the likelihood of an animal's adopting inefficient behavioral strategies, such as seen in impulsivity.

Region-specific and receptor targeted parsing of the serotonin system is historically difficult, due to the system's complexity and the limitations of some tools in distinguishing varied components. For example, serotonergic neurons can corelease glutamate throughout the brain (Sengupta et al., 2017; Ren et al., 2018; Belmer et al., 2019; Wang H. L. et al., 2019). Monitoring DRN activity doesn't distinguish between the effect of serotonin and glutamate release, even when neurons are targeted in projection-specific approaches. Global manipulations of the serotonergic system, such as SERT KO or inhibition, produce manifold compensatory changes beyond simply altering the level of serotonin in the synapse (Homberg et al., 2007). Historically, the primary technique available for monitoring serotonin in vivo was microdialysis, which is sensitive to only one of the multiple timescales at which serotonergic neurons appear to operate (Cohen et al., 2015). Fortunately, recent advances in fluorescent-based in-vivo monitoring techniques now allow for direct monitoring of serotonin release at time scales compatible with understanding its role in reward processing, motivation, and impulsivity (Unger et al., 2020; Dong et al., 2021; Wan et al., 2021).

\section{Reward and Impulsive Action}

In addition to classical conditioning, reward processing is central to instrumental behavior, and increased impulsivity could result from the overvaluation or increased motivation for reward, which override the negative consequences associated with taking action. Difficulty in withholding or stopping ongoing responding 
for reward in tests of instrumental behavior is a defining characteristic of impulsive action. Examples of paradigms used to assess this component of impulsivity include the $\mathrm{Go} / \mathrm{No}$ go (measuring the decreased ability to withhold responding when presented with a no-go cue), 5-choice serial reaction time test (5CSRTT; assessing premature responding), stop signal reaction time test (SSRT; testing the decreased ability to halt ongoing responding), and differential reinforcement of low rate responding (DRL; measuring the decreased ability to withhold responding for a wait period).

Importantly, an increased impulsive action phenotype may influence behavioral readouts in other operant paradigms testing motivation, such as random ratio and progressive ratio. Changes in excitatory responding (actions normally taken in pursuit of reward), for example the vigor of responding, which are subserved by changes in reward circuitry (Bailey et al., 2016, 2018) may make inhibiting the response more difficult. This could drive increased/disordered responding seen in these operant tasks, as well as in clinical cases of increased impulsivity. For example, dysfunctional reward processing is frequently comorbid in psychiatric disorders characterized by levels of increased impulsivity, including substance use, gambling disorders, and schizophrenia (Bjork et al., 2004; Monterosso et al., 2005; Rubio et al., 2008; Billieux et al., 2012). Preclinically, rats that show high levels of premature responding in the 5CSRTT are also more sensitive to cue-induced reinstatement of sucrose-seeking (Diergaarde et al., 2009). The question remains if the dysregulated impulsivity is causally linked to the reward system dysfunction. We recently developed a paradigm to show that increasing reward value on a trial-by-trial basis can lead directly to increased impulsive action in a Go/No-go paradigm (Desrochers et al., 2021). Future studies can expand on this to attempt to ameliorate disordered impulsivity by normalizing the aberrant reward processing.

Approaches to dissect the underlying neural circuits of co-occurring reward process and inhibitory dysfunction can determine if the neural circuit dysregulation is subserved by convergent mechanisms. Many of the same brain areas noted to be involved in reward and motivation have also been implicated in impulsive action. In particular, the NAc and its core and shell subregions have been extensively studied for their individual roles in impulsive action through reaction time tests, with pharmacological manipulations and deep brain stimulation of the shell subregion causing elevated premature responding (Sesia et al., 2010; Feja et al., 2014). Optogenetic stimulation of projections from the VTA to the NAc shell also increased premature responding during a long inter- trial interval in the 5CSRTT (Flores-Dourojeanni et al., 2021). Additionally, prefrontal cortical regions modulate impulsive action, though they are more often associated with assigning value to different decisions and choosing between actions (OFC, mPFC). Specifically, in an imaging study in humans, Mechelmans et al. (2017) found that impulsivity for high value reward cues in a 4CSRTT was accompanied by increased activity in the mOFC and in a monetary incentive delay task was associated with increased functional connectivity between the STN and left mOFC. In a rodent study of the 5CSRTT, rats that tended to respond prematurely had alterations in oscillatory patterns in the mPFC and NAc, which may cause abnormal reward encoding resulting in increased impulsive action (Donnelly et al., 2014).

The alterations in reward-related behavior in impulsivity could also be the result of impaired action selection supported by the dorsal striatum, which is important when there is an instrumental contingency between response and reward, as in many tests of impulsive action (Balleine et al., 2007; Corbit and Janak, 2007, 2010). Pharmacological manipulations of serotonin and glutamate receptors in the dorsal striatum modulate premature responding in the 5CSRTT (Agnoli and Carli, 2012). The varied regions associated with the control of impulsive action highlight the importance of considering reward processing in the study of impulsivity, as well as suggest that there may be many ways to cause an impulsive action "phenotype" through modulation of different behavioral endophenotypes. Behavioral analysis which considers the learning, hedonic, and motivational contributions to pathological cases of impulsivity may help clarify and point toward more specific neural targets for treatment.

\section{Contributions of Serotonin to Impulsive Action Through Reward}

Given that serotonin signaling is involved in many aspects of reward processing, it is relevant to consider how the influence of serotonin on reward contributes to its effect on impulsivity. As discussed in prior sections, most, if not all, rodent assays of action impulsivity involve approach toward appetitive cues and outcomes, and are therefore confounded by reward processing. As such, the effects of manipulations to serotonin signaling on tests of impulsive action may in some cases arise from effects on reward responsivity. Directly assessing the effects of experimental manipulations of serotonin signaling on reward related alterations is helpful to accurately interpret the effects in traditional tests of impulsivity.

Serotonin enables appropriate waiting for reward (Eagle et al., 2009; Miyazaki et al., 2014), and activation of serotonergic neurons in the DRN is correlated with (Miyazaki et al., 2011) and causally linked (Miyazaki et al., 2014) to waiting. The OFC, in addition to its previously described involvement in reward processing, mediates at least some of serotonin's action in impulse control, as stimulating serotonin release in the OFC almost fully recapitulates the effect of DRN stimulation on waiting (Miyazaki et al., 2020). These two sets of functions are likely intertwined. Serotonergic signaling in the OFC is often associated with impulsive choice (Wischhof et al., 2011; Darna et al., 2015), in part because of its well established contributions to tracking and representing the value of reward predictive cues (Clarke et al., 2007; Nonkes et al., 2010). However, there is evidence that it is also involved in the capacity to withhold premature responses, to stop ongoing behavior, and to perform other forms of response inhibition (Chudasama et al., 2003; Eagle et al., 2008b; Mechelmans et al., 2017). Yet, the OFC is not necessary for pure motor inhibition (Swick et al., 2008) nor does it encode the value of actions themselves but rather that of affective stimuli (Rolls, 2004; Rudebeck et al., 2008). Thus, the understanding of OFC serotonergic function in impulsivity should not be restricted to a choice vs. action binary nor to a pure response 
inhibition framework. Rather, it appears related to the ability to withhold behavior generally and likely does so through its role in outcome value encoding.

Serotoninergic modulation of prospective reward encoding within the OFC is heterogeneous (Zhou et al., 2015), as are its effects on OFC neuronal activity (Wright et al., 2017, 2021). During reward prediction, OFC activity is distinct from baseline yet characterized by neither a gross increase nor decrease in activity (Shobe et al., 2017). This "activity-silent" state (Stokes, 2015) is similar to the heterogeneous responses observed in response to serotonin tone. The OFC communicates information regarding the prospective value of expected rewards to other limbic structures, its connectivity with the NAc being particularly important (Meyer and Bucci, 2016b; Wang Z. et al., 2019), thereby permitting the usage of that value in the computation of whether or not to initiate a behavioral response.

The mesolimbic pathway is another circuit in which serotonin regulates reward encoding and the generation of motivated behavior. In humans, genetic variation in a serotonin production enzyme, tryptophan hydroxylase-2, is associated with increased impulsivity and increased responsivity of NAc to reward (Neufang et al., 2016). Gross manipulations to serotonin tone within the limbic system in rodents alter motivational drive. For example, the impulsivity produced by serotonin depletion in the NAc does not appear to reflect an alteration in response inhibition (Fletcher et al., 2009). Specifically, while it increases the rate of responding in the DRL, it does not alter burst responding nor does it increase premature responding in the 5CSRTT. More specific manipulations to serotonergic signaling through either $5-\mathrm{HT}_{1 \mathrm{~B}}$ (by gene knockout) or $5-\mathrm{HT}_{2} \mathrm{C}$ receptors (by receptor antagonist) impairs response inhibition while also increasing mesolimbic DA release (Pennanen et al., 2013; Nautiyal et al., 2015), suggesting that these receptors may mediate the general effect of serotonin on NAc activity and behavior. The 5$\mathrm{HT}_{1 \mathrm{~B}}$ receptor is a likely substrate through which serotonin may influence reward and impulsive action: $5-\mathrm{HT}_{1 \mathrm{~B}}$ receptor knockout increases reward valuation in a lickometer test and false alarm rate for no-go trials in the Go/No-go test (Desrochers et al., 2021), and restoring $5-\mathrm{HT}_{1 \mathrm{~B}}$ receptor expression in adulthood reverses both action impulsivity and altered dopamine signaling in the NAc (Nautiyal et al., 2015). Interestingly, overexpression of $5-\mathrm{HT}_{1 \mathrm{~B}}$ receptors in NAc shell projections to the VTA also increases the rewarding effects of drugs of abuse (Neumaier et al., 2002; Furay et al., 2011). Additionally, reduced binding of these receptors in the NAc and VP is associated with major depressive disorder, of which insensitivity to reward (anhedonia) is a principal symptom (Murrough et al., 2011). More generally, $5-\mathrm{HT}_{1 \mathrm{~B}}$ signaling is linked to depression-like behavior in animal models (Svenningsson et al., 2006) and to cocaine or social reward through is localization in the NAc, (Dölen et al., 2013; Fontaine et al., 2021). Thus, 5-HT $1 \mathrm{~B}$ under- or over-expression can contribute to altered reward processing, suggesting that normal function requires maintenance of balanced signaling.

In sum, there is evidence that serotonergic regulation of impulsivity occurs, in part, at the level of reward processing. Described above are proposed roles for serotonin in linking these processes in the OFC and mesolimbic pathway. However, the extent of serotonin's involvement in such a link in many other regions remains to be characterized. Figure 2A summarizes areas targeted by serotonergic neurons that are involved in reward and impulsivity which may be promising targets for such characterization. Research that seeks to bridge the gap between reward and impulsivity-such as through the use of batteries of behavioral assays that provide information across multiple dimensions-would greatly enhance our understanding of not only impulse control, but also the processes by which motivated behaviors and impulses are generated.

\section{THE BRAKE: CONTRIBUTIONS OF INHIBITORY CONTROL TO IMPULSIVITY}

Alternatively to increased reward drive, disordered impulsivity can be considered as a failure of inhibitory processes, even colloquially described as a lack of "self-control." In the impulsive action subtype of impulsive behavior, this presents as deficits in preventing responding or stopping ongoing responding. Withholding an action, or learning that the absence of response results in reward, is an action-outcome association that is necessary for successful performance in standard tests of impulsive action. This action-outcome association opposes the initially learned excitatory association in which the action led to reward. The ability to withhold responding, or inhibitory control, is often ascribed to higher executive functions and decision-making processes controlled by cortical areas, which act to modulate subcortical regions involved in "drive" (Dalley et al., 2011; Bari and Robbins, 2013). However, deficits in response inhibition also arise locally within lower neural areas involved in the volitional process (such as the NAc, which is usually associated with the "drive" component but may also have an inhibitory role). There also may be separable component processes underlying the acquisition/learning and the expression of inhibitory control, which would require carefully designed behavioral studies to separate.

\section{Inhibition and Classical Conditioning}

Learning about inhibitory associations is an important component to consider in understanding response inhibition in impulsive action. This is distinct from the behavioral/motor expression. Deficits in inhibitory learning could be a cause of deficits in response inhibition, or alternatively, could be intact with the impulsivity arising at other levels of processing. While impulsivity itself is not defined in the context of classical conditioning, a behavioral output may appear impulsive if there are underlying deficits in inhibitory learning. For example, an impulsive behavior could result from the lack of learning of the response omission - reward association, or from a decreased ability to withhold a response. The acquisition of inhibitory learning has been studied extensively in the context of classical conditioning.

A primary area of inhibitory learning is extinction, where a new inhibitory memory is acquired to compete against a previously established excitatory memory. Importantly, extinction is not an erasure of a memory, but rather a competition 
of parallel associations, where old memories/behaviors can spontaneously renew (Bouton, 1993; Todd et al., 2014; Bouton et al., 2021). A deficit in the formation of the new inhibitory association or a failure of this association to successfully compete with the excitatory association, could result in altered impulsivity in classic tests of impulsive action. However, though there are many parallels between Pavlovian and operant extinction, there are also clear dissociations; for example, Pavlovian extinction does not usually transfer between conditioned stimuli, but operant extinction does (Trask et al., 2017; Bouton et al., 2021). Neurally, both the BLA and the infralimbic cortex, among others, are all involved in both Pavlovian and operant extinction, but the NAc shell is especially implicated in operant extinction (Millan and McNally, 2011; reviewed in Bouton et al., 2021). The hippocampus also seems to be involved in behavioral inhibition during extinction, as lesions to this region prevent extinction of a previously classically conditioned appetitive stimulus (Chan et al., 2003). All of these regions have also been implicated in the modulation of impulsive action, suggesting that deficits in extinction behavior may be involved in some presentations of impulsivity, or rely on dysfunction in similar neural mechanisms.

Another Pavlovian behavioral paradigm which could be useful in understanding the role of inhibitory learning in impulsive action is conditioned inhibition (reviewed by Sosa and dos Santos, 2019). Conditioned inhibition is a form of classical inhibitory learning where an inhibitory cue indicates the absence of an outcome when it is paired as a compound with a normally excitatory cue (A+, AX-; Pavlov, 1927). This inhibitor cue can then "transfer" and reduce responding when paired with other excitatory cues (BX-; Holland, 1989). Impulsive subjects which have diminished inhibitory control in operant paradigms may also fail to inhibit responding for the inhibitor-excitor compound cue in a test of Pavlovian conditioned inhibition, potentially suggesting common underlying mechanisms. Accordingly, $\mathrm{He}$ et al. (2011) found decreased expression of conditioned inhibition in a clinical population with personality disorders, often characterized by disinhibition and impulsivity. However, to dissociate the acquisition of this inhibitory learning from behavioral expression, acute time-limited experiments using optogenetic or chemogenetic inactivation of relevant neural targets during training vs. recall testing may be necessary.

Another version of Pavlovian inhibitory learning is negative occasion setting in which an inhibitory cue indicates that an outcome will not occur when presented in sequence with a normally excitatory cue $(\mathrm{A}+, \mathrm{X} \rightarrow \mathrm{A}-)$. In this case, the conditioning is specific to the trained set of cues, and the inhibitor does not usually transfer to a different excitatory cue (Holland, 1989). Adolescent rats take longer to discriminate between reinforced and non-reinforced trials in a negative occasion setting paradigm when compared to preadolescents and adults, possibly due the functional immaturity of the PFC during this developmental period (Meyer and Bucci, 2017). Indeed, the prelimbic region of the PFC is necessary for learning this discrimination negative occasion setting, but not expressing it following training (MacLeod and Bucci, 2010). Additionally, these findings were replicated in a conditioned inhibition paradigm, where Meyer and Bucci
(2014) found that lesions of the prelimbic region of the PFC decreased acquisition of conditioned inhibition learning, whereas lesions of the infralimbic cortex decreased behavioral expression following successful discrimination. Further testing inhibitory learning processes in established models for impulsive action or clinical populations are important next steps. These classical conditioning experiments could help elucidate the underlying behavioral/cognitive deficits present in specific cases of impulsivity, as well as suggesting potential shared neural substrates.

\section{Contributions of Serotonin to Inhibitory Classical Conditioning}

Though serotonin is strongly implicated in behavioral inhibition in instrumental conditioning, it is also involved in the acquisition and expression of inhibitory learning in these classical conditioning experiments. Lister et al. (1996) found that ablation of serotonergic pathways in rats reduced the acquisition of inhibitory associations, but left excitatory associations intact in a conditioned inhibition task. Knockout of the serotonin-transporter in rats also results in reduced latent inhibition, which is when a previously unpaired stimulus acquires inhibitory properties (Nonkes et al., 2012). Additionally, serotonin depletion impairs both Pavlovian and instrumental reversal learning, resulting in perseverative responding for a previously rewarded or safe stimulus (Cools et al., 2008; Kanen et al., 2021). This could be interpreted as a failure of behavioral flexibility, or as a failure to learn/express a new inhibitory association. One concept that unites these findings together is that serotonin signaling may play a role in the processing of aversive outcomes (including low reward, reward absence, or punishment; Crockett et al., 2012; Geurts et al., 2013; Unger et al., 2020). Specifically, serotonergic dysfunction (induced by tryptophan depletion) may cause a more positive estimation of the value of aversive outcomes, resulting in disinhibition of responding in both classical and operant conditioning (Dayan and Huys, 2008).

Serotonin is also involved in the extinction of classical conditioning. However, most research in this area has been conducted in fear extinction, rather than extinction of appetitive cues which correspond better to the inhibitory associations necessary for typical reward-based tests of impulsive action (though Pereyra et al., 2021b do describe serotonin effects on extinction of operant responding for reward). In fear conditioning, knockout of the serotonin transporter impairs extinction recall, though here the effect may be through the retention or expression, rather than the acquisition, of the new inhibitory association (Wellman et al., 2007; Narayanan et al., 2011; furthered reviewed in Bauer, 2015). Consideration of extending the role of serotonin signaling from operant behavioral inhibition to appetitive classical inhibitory conditioning (e.g., in tests of conditioned inhibition, negative occasion setting, and extinction) may help parse the behavioral and circuit mechanisms through which serotonin impacts inhibition. Importantly, inhibitory learning could be an important avenue through which serotonin modulates impulse control. 


\section{Impulsive Action and Response Inhibition}

Though disordered impulsivity could occur because of differences in inhibitory Pavlovian associations, it is defined in the context of operant conditioning requiring inhibition of an action to obtain reward. Nevertheless, similarly to classically conditioned response inhibition, the inhibitory "brake" seems to rely heavily on prefrontal regions upstream of subcortical reward areas (see Bari and Robbins, 2013 for an extensive review of their search). In humans, several fMRI studies have identified neural correlates of inhibitory control during tests of impulsive action. Activity in the vlPFC was associated with successful response inhibition in no-go trials for larger monetary rewards in an incentivized inhibition task (Leong et al., 2018). Additionally, using a stop signal task, Weafer et al. (2019) found that decreased activity in the right PFC during response inhibition was associated with higher left ventral striatum activity during reward receipt, suggesting negative functional association between inhibitory control and reward drive modulated through cortico-striatal connections. The anterior cingulate cortex (ACC) has also been implicated in impulse control in subjects with ADHD (Baytunca et al., 2021), and its activity is related to error processing in a Go/No-go task (Hester et al., 2004).

There is also a large literature investigating the neural circuitry underlying cortical control of response inhibition in preclinical models. Pharmacological inactivation of various regions of the $\mathrm{mPFC}$, especially the prelimbic and infralimbic regions, resulted in a loss of inhibitory control on no-go trials in a response inhibition task which included shock punishments (Verharen et al., 2019). Chemogenetic activation of the vmPFC to NAc shell pathway decreases motor impulsivity in a 1CSRTT and binge-eating in rats, suggesting that these higher order areas have inhibitory control over reward processing (Anastasio et al., 2019). Indeed, using optogenetics, Li et al. (2020) found that another cortical-subcortical connection from the dmPFC to the STN in mice was important for response inhibition in a Go/Nogo task. In the ACC, inhibitory G proteins are involved in the control of premature responding in the 5CSRTT (van der Veen et al., 2021). Interestingly, these studies manipulate their pathways/regions only after subjects acquired baseline training performance, suggesting that these pathways play a role in the behavioral expression of inhibition, not necessarily the learning itself. There is also convergent human and animal evidence for a role of the OFC in response inhibition (reviewed in Winstanley et al., 2010), however, single-unit recordings by Bryden and Roesch (2015) revealed that OFC neuron activity seems to support the separation of similar actions rather than inhibition independently.

Beyond the cortex, there is also evidence for the contribution of subcortical areas to response inhibition during tests of impulsive action. Deep brain stimulation of the NAc core in rats decreased impulsivity as measured by premature responding in a reaction time test, while stimulation of the NAc shell increased impulsivity, suggesting that the different subregions of the NAc may functionally support both excitation and inhibition in pursuit of reward (Sesia et al., 2008). Also, in the NAc, local inhibitory control may occur through the activity of fastspiking interneurons, which seem to constrain impulsive action in the 5CSRTT, likely by inhibiting signaling of medium spiny neurons (Pisansky et al., 2019). Finally, dopamine signaling in the dorsal striatum is also important for response inhibition in a stop-signal task (Robertson et al., 2015). Together, all these studies suggest that the inhibitory control of impulsive action relies both on cortical and local sub-cortical control of reward processing areas.

\section{Contributions of Serotonin to Inhibitory Control of Impulsivity}

Overall, the serotonin system is well-positioned to impact impulsive action through its ability to modulate components of this inhibitory control system. Serotonergic neurons from the DRN innervate many cortical (and some subcortical) regions implicated in behavioral inhibition (Figure 2B), and signal through a number of different serotonin receptors (Table 1). Classic research which implicates serotonin in the regulation of anxiety behavior, is sometimes extended to the behavioral inhibition concept. For example freezing behavior in response to aversive stimuli (e.g., Wise et al., 1973) or a lack of approach in a conflict test (Graeff et al., 1997) may be viewed as inhibited behavioral responses. However, while serotonergic neurons do respond to such anxiogenic and aversive stimuli (Wise et al., 1973; Ren et al., 2018), clinical observations failed to support the theory that serotonergic signaling generated aversion. Soubrié (1986) proposed a simple resolution to this apparent conflict: serotonin encoded not anxiety but the "stop" signal that such an emotional experience occasions. Subsequently, a great deal of work has sought to characterize the precise nature of serotonin's role in behavioral inhibition in both punishment (e.g., Crockett et al., 2009) and reward (Clark et al., 2005; Eagle et al., 2009; Nonkes and Homberg, 2013; Miyazaki et al., 2014, 2020; Nonkes et al., 2014; Odland et al., 2021).

Whereas serotonin's contributions to reward can be assessed directly outside of tests of impulsivity (as discussed), its role in behavioral inhibition is harder to extricate since tests of impulsive action are most commonly tests of behavioral restraint. Nevertheless, both behavioral evidence and a review of areas in which serotonin acts on behavioral restraint support a role for serotonin in "brake" processes. Global 5-HT depletion increases premature responding in the 5CSRT task (Harrison et al., 1997; Winstanley et al., 2004) and impairs behavioral restraint on "no-go" trials in the Go/No-go task (Harrison et al., 1999a; Masaki et al., 2006). Critically, the deficits induced by such depletion are specific to impulse control during the action preparation phase of behavior: both the ability to cease ongoing behavior, tested with the stop-signal reaction time task (Eagle et al., 2008a), and preference for smaller, immediate rewards in delay discounting (Winstanley et al., 2003; Worbe et al., 2014) are insensitive to serotonergic manipulation. In the other direction, stimulating serotonergic neurons enhances the ability to wait for reward delivery in "patience" based tasks, but is not, itself, rewarding (Miyazaki et al., 2014, 2018; Fonseca et al., 2015). Further, serotonergic release differentially mediates 
waiting through actions in different cortical areas (Miyazaki et al., 2020). Specifically, stimulation of 5-HT release in the mPFC improves "patience" only during periods of waiting uncertainty (Miyazaki et al., 2020). Because the mPFC is generally thought to regulate the timing of behavior and encodes event and delay durations (Narayanan and Laubach, 2006; Kim et al., 2009; Xu et al., 2014; Tiganj et al., 2017), the selectivity of the effect of stimulated release suggests that prefrontal serotonin may contribute to action inhibition through a role in response timing. The many functions of the mPFC are mediated by dissociable, heterogeneous populations of projection neurons, which display a wide range of responses to affective stimuli (Grant et al., 2021) and regulate discrete aspects of motivated behavior (Otis et al., 2017, 2019). Serotonin is well positioned to modulate general cortical synchrony and the balanced activity of output pathways through tuning the activity of both inhibitory microcircuits and projection neurons (Puig and Gulledge, 2011; Dembrow and Johnston, 2014), as well as regulating the general cortical response to affective stimuli (Pereyra et al., 2021a).

The $\mathrm{mPFC}$ receives strong serotonin innervation from the DRN and is critical for behavioral control through both action selection and timing. Paradoxically, though elevated tonic extracellular levels of 5-HT in $\mathrm{mPFC}$ correlate with higher impulsive action in the 5CSRTT (Dalley et al., 2002), directly stimulating serotonin release in $\mathrm{mPFC}$ terminals increases wait times (i.e., decreases impulsivity) in a delayed reward task (Miyazaki et al., 2020). Resolution of this conflict will likely require characterization of both phasic serotonin release in the $\mathrm{mPFC}$ and neural responses to said release during such tasks. Furthermore, serotonergic neurons co-release glutamate in numerous other areas, including the amygdala (Sengupta et al., 2017) and VTA (Wang H. L. et al., 2019) while the presence of glutamate-serotonin co-transmission has not been characterized within the MPFC, DRN terminals in this area show robust coexpression of SERT and VGLUT3 (Belmer et al., 2019), indicating that the contribution of glutamatergic signaling to DRN stimulation must be considered.

The ACC is another locus for behavioral control that is modulated by serotonin. Altered serotoergic signaling in humans is associated with altered ACC activity that correlates with impoverished action monitoring and behavioral restraint (Holmes et al., 2010; Hong et al., 2018). 5- $\mathrm{HT}_{1 \mathrm{~B}}$ receptor binding within the ACC is strongly associated with inhibiting responses to stimuli in an emotional Go/No-go task (da Cunha-Bang et al., 2017). Serotonin also acts at 5-HT $1 \mathrm{~A}$ (Tian et al., 2017) and complexed 5- $\mathrm{HT}_{2 \mathrm{~A} / \mathrm{C}}$ receptors (Price et al., 2019) within the ACC. However, the precise role that these latter receptors play in behavior remains unclear. The behavioral consequences of $5-\mathrm{HT}_{2 \mathrm{C}}$ activation or inactivation are mixed, likely due to the lack of receptor specificity in some pharmacological manipulations, with some drugs impacting both the $2 \mathrm{C}$ and $2 \mathrm{~A}$ receptors. Across multiple studies, systemic $5-\mathrm{HT}_{2} \mathrm{C}$ agonism has been observed to increase (Koskinen et al., 2000b; Blokland et al., 2005) or decrease (Fletcher et al., 2007, 2013) premature responding in the 5CSRTT. More specific systemic antagonism of the $5-\mathrm{HT}_{2 \mathrm{~A}}$ receptors reduces premature responding in the
5CSRTT (Fletcher et al., 2007). Interestingly, when infused directly into the ACC, a $5-\mathrm{HT}_{2 \mathrm{~A} / 2 \mathrm{C}}$ agonist (which had increased impulsive action in the 5CSRTT when administered systemically in the same study) had no effect on impulsivity (Koskinen et al., 2000b). Though the precise functional roles of ACC serotonin receptors clearly remain to be determined, they are likely related to the ACC's established roles in both maintaining representations of desired outcomes and inhibiting behaviors that interfere with outcome acquisition (Berkman et al., 2012). These functions of the ACC are accomplished, in part, by cortical inhibition of stimulus-response associations within the striatum to permit the control of behavior by action-outcome contingencies (Cools et al., 2008), and serotonin is a known modulator of these projections.

Serotonin also acts directly in both ventral and dorsal striatum, important targets of both the MPFC and ACC in their regulation of behavior, to regulate motivation and impulsivity. While serotonin in the ventral striatum counters anticipatory encoding of proximal rewards, serotonin in the dorsal striatum enables prospective encoding of distal rewards (Tanaka et al., 2007). In the latter system, serotonin facilitates information processing through the interplay between cortical input and $5-\mathrm{HT}_{2 \mathrm{~A}} / 5-\mathrm{HT}_{2 \mathrm{C}}$ signaling (Agnoli and Carli, 2012). In the ventral striatum both $5-\mathrm{HT}_{2 \mathrm{~A}}$ and $5-\mathrm{HT}_{2 \mathrm{C}}$ antagonism reduce impulsivity, and $5-\mathrm{HT}_{2 \mathrm{~A}}$ antagonism appears to do this by generally suppressing motivated responding (Robinson et al., 2008). Serotonin depletion in the NAc increases the rate of responding in the DRL without appearing to influence motor impulsivity and is theorized to reflect a decreased tolerance for delayed reward (Fletcher et al., 2009). However, directly stimulating serotonergic terminals in the NAc does not increase waiting in a patience-based task (Miyazaki et al., 2020). Thus, serotonergic signaling within the ventral striatum appears to mediate proximal reward response and approach drive, while within the dorsal striatum it facilitates control of behavior in the face of delayed rewards.

In summary, the literature supports the following conclusions: (1) Serotonin receptors are positioned to regulate cortical microcircuits and projection neurons. (2) Serotonergic manipulations within prefrontal cortices and striatal outputs alter impulsive behavior. (3) The described functions of these cortical regions align best with "brake" processes in behavioral restraint rather than "drive" processes. To build a model of serotonergic impulsivity-regulation within cortical circuits, these ideas would ideally be integrated in a cohesive framework. For example, future work could characterize the role and impact of serotonergic signaling on the activity of functionally discrete cortical subpopulations (e.g., Hart et al., 2018; Grant et al., 2021). Causally linking serotonergic signaling within corticostriatal circuits to behavioral inhibition would be the next step. Behavioral assays targeted at cortical control processes including those targeting timing or action monitoring may help identify specific "brake" functions altered in impulsive animals. Meanwhile, tests sensitive to altered reward and motivation may serve to exclude changes in "drive" processes. 


\section{DISCUSSION: IMPULSIVITY AS AN IMBALANCE OF SYSTEMS AND FUTURE DIRECTIONS}

Through this review, we have provided an overview of the behavioral and neural systems underlying impulsive action. Dysregulations of either reward or inhibition can create an imbalance of the neural systems responsible for impulse control. Neurally, we suggest that widespread DRN serotonergic projections (Figure 2) place serotonin, signaling through its various receptor types (Table 1), in a prime position to modulate both the excitatory and inhibitory components of these systems. Indeed, there may be multiple serotonin subsystems which separably mediate responses to rewarding or aversive outcomes (Ren et al., 2018). Either excess excitation or decreased inhibitory control could result in increased impulsive action as observed by a decreased ability to stop or withhold responding. In this case, the initially learned "go" association overrides the "no-go" or stop association. Increased impulsivity could also be the result of altered activity in both drive and brake processes. Ultimately, both processes compete over controlling the same endpoint: motor output. For animals to achieve efficient, flexible behavior, the drive and brake circuitry must each be responsive to task demands in guiding action selection.

Adolescence is an interesting case which allows us to probe the role of these two processes and how serotonin influences the balance. Specifically, adolescence is a developmental period characterized by increased impulsivity, risky decision making, and hyper reward-sensitivity. In the dimension of impulsive action, compared to children and adults, teenagers have more false alarms for no-go cues in the Go/No-go test (Somerville et al., 2011; Dreyfuss et al., 2014). This heightened impulsive action is thought to be the result of the linear development of the PFC and the nonlinear development of the ventral striatum and other components of the reward system, which peak in sensitivity during adolescence (Blakemore and Robbins, 2012). This results in an imbalance between the subcortical systems which motivate behavior and the cortical systems providing inhibitory control compared to childhood and adulthood (Casey et al., 2011). Substance use disorders have also been considered through a similar lens, with both increased appetitive drive and disordered executive control potentially resulting in impulsive behavior, though the extent to which impulsivity is causal or resultant to addiction is unclear (Bechara, 2005; Camchong et al., 2014; Jentsch et al., 2014; Kozak et al., 2019).

Importantly, the imbalance of reward and inhibitory processing could be the result of dysfunction of many different regions, cell types, and/or receptor types, which may each result in an impulsive action phenotype, albeit through different neural and behavioral processes. Therefore, careful dissections of the processes which contribute to impulsive action allows for the fractionation of different paths to an overall impulsive phenotype. Testing may use non-traditional tests for the study of impulsivity, including the consideration of Pavlovian and instrumental learning processes, the expression of behavioral inhibition, and reward processes. For example, in Figure 3, we show a chart with reward and behavioral inhibition as hypothetical dimensions characterizing different behavioral measures. Notably, tests like taste reactivity primarily measure a reward-related behavior; on the other hand tests like the Go/No-go are considered measures of impulsive action, but are also influenced by reward value (Desrochers et al., 2021). Desrochers et al. found that increasing reward quantity increases false alarm rates for no-go trials in control mice, while decreasing reward quantity reduced this measure in normally impulsive mice lacking the $5-\mathrm{HT}_{1 \mathrm{~B}}$ receptor. This suggests that some traditional measures of impulsive action are intrinsically tied to reward related behaviors. However, we highlight the idea that additional approaches to measuring impulsivity in the absence of learned appetitive motivators may allow the dissociation of reward processes from behavioral inhibition (see Figure 3). It is unclear to us whether any existing tests could specifically be used to measure impulsive action in the absence of reward. A possibility may be active avoidance, where animals learn to avoid the side of a shuttle box associated with an aversive outcome. Subjects with decreased behavioral inhibition may have enhanced active avoidance behaviors (more rapid acquisition of the behavior) in this task; indeed, selectively bred Roman-high avoidance rats also have increased premature responding in the 5CSRTT compared to low-avoidance rats (Moreno et al., 2010). Additionally, in these rat strains, $5-\mathrm{HT}_{2 \mathrm{~A}}$ binding levels are higher in the high-avoidance rats and correlate with impulsivity

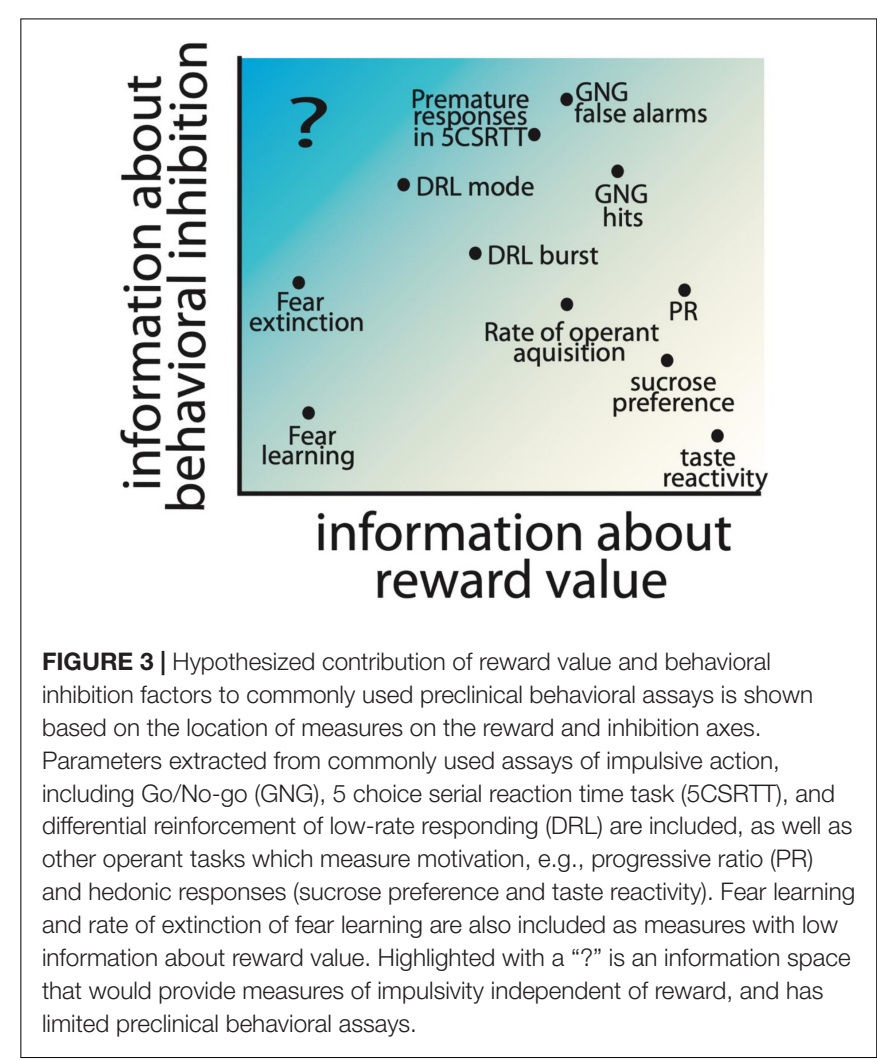


in the 5CSRTT (Klein et al., 2014). This suggests a role for serotonin signaling in behavioral inhibition, independent of reward, which could be further studied using an active avoidance test. More studies testing traditional models for pathological impulsivity in active avoidance paradigms would be helpful to understand if this would be a useful approach to measuring impulsive action without an appetitive conditioning paradigm.

In conclusion, we support consideration of components of impulsivity beyond the overarching subtypes (i.e., action vs. choice), to include specific cognitive and behavioral substrates. Studies of disordered impulse control, both in human and animal models, would ideally use multiple and varied behavioral tests to determine the underlying component processes and tease apart influences of reward from inhibitory control. The understanding of the contributions of these processes can provide tractable targets for pursuing neural circuit mechanisms and potentially more individualized treatment approaches for pathological impulsivity. In particular, we propose that serotonin signaling is an important mechanism to explore in this context

\section{REFERENCES}

Acheson, A., Richard, D. M., Mathias, C. W., and Dougherty, D. M. (2011). Adults with a family history of alcohol related problems are more impulsive on measures of response initiation and response inhibition. Drug Alcohol Depend. 117, 198-203. doi: 10.1016/j.drugalcdep.2011.02.001

Acosta, J. I., Boynton, F. A., Kirschner, K. F., and Neisewander, J. L. (2005). Stimulation of 5-HT1B receptors decreases cocaine- and sucrose-seeking behavior. Pharmacol. Biochem. Behav. 80, 297-307. doi: 10.1016/j.pbb.2004.12. 001

Agnoli, L., and Carli, M. (2012). Dorsal-striatal 5-HT 2A and 5-HT 2C receptors control impulsivity and perseverative responding in the 5-choice serial reaction time task. Psychopharmacology 219, 633-645. doi: 10.1007/s00213-011-2581-0

Ahrens, A. M., Meyer, P. J., Ferguson, L. M., Robinson, T. E., and Wayne Aldridge, J. (2016). Neural activity in the ventral pallidum encodes variation in the incentive value of a reward cue. J. Neurosci. 36, 7957-7970. doi: 10.1523/ JNEUROSCI.0736-16.2016

Amiez, C., Joseph, J. P., and Procyk, E. (2006). Reward encoding in the monkey anterior cingulate cortex. Cereb. Cortex 16, 1040-1055. doi: 10.1093/cercor/ bhj046

Anastasio, N. C., Stutz, S. J., Price, A. E., Davis-Reyes, B. D., Sholler, D. J., Ferguson, S. M., et al. (2019). Convergent neural connectivity in motor impulsivity and high-fat food binge-like eating in male Sprague-Dawley rats. Neuropsychopharmacology 44, 1752-1761. doi: 10.1038/s41386-019-0394-8

Bailey, L. S., Bagley, J. R., Dodd, R., Olson, A., Bolduc, M., Philip, V. M., et al. (2021). Heritable variation in locomotion, reward sensitivity and impulsive behaviors in a genetically diverse inbred mouse panel. Genes Brain Behav. 20, e12773. doi: $10.1111 / \mathrm{gbb} .12773$

Bailey, M. R., Goldman, O., Bello, E. P., Chohan, M. O., Jeong, N., Winiger, V., et al. (2018). An interaction between serotonin receptor signaling and dopamine enhances goal-directed vigor and persistence in mice. J. Neurosci. 38, 2149-2162. doi: 10.1523/JNEUROSCI.2088-17.2018

Bailey, M. R., Simpson, E. H., and Balsam, P. D. (2016). Neural substrates underlying effort, time, and risk-based decision making in motivated behavior. Neurobiol. Learn. Mem. 133, 233-256. doi: 10.1016/j.nlm.2016.07.015

Balleine, B. W., Delgado, M. R., and Hikosaka, O. (2007). The role of the dorsal striatum in reward and decision-making. J. Neurosci. 27, 8161-8165. doi: 10. 1523/JNEUROSCI.1554-07.2007

Balleine, B. W., Fletcher, N., and Dickinson, A. (1996). Effect of the 5HT1A agonist, 8-OH-DPAT on instrumental performance in rats. Psychopharmacology (Berl) 125, 79-88. doi: 10.1007/BF02247396 to understand the behavioral and neural bases of the control of impulsive action.

\section{AUTHOR CONTRIBUTIONS}

$\mathrm{SD}, \mathrm{MS}$, and $\mathrm{KN}$ contributed to the ideas, wrote the manuscript, and approved the final version.

\section{FUNDING}

This work was funded by NIH R00 MH106731 and R01 MH126178 to KN.

\section{ACKNOWLEDGMENTS}

We would like to thank Peter Balsam for helpful conversations on these ideas. Figures 1, 2 were created using Biorender.com.

Bari, A., and Robbins, T. W. (2013). Inhibition and impulsivity: behavioral and neural basis of response control. Prog. Neurobiol. 108, 44-79. doi: 10.1016/j. pneurobio.2013.06.005

Bauer, E. P. (2015). Serotonin in fear conditioning processes. Behav. Brain Res. 277, 68-77. doi: 10.1016/j.bbr.2014.07.028

Baytunca, M. B., de Frederick, B., Bolat, G. U., Kardas, B., Inci, S. B., Ipci, M., et al. (2021). Increased cerebral blood flow in the right anterior cingulate cortex and fronto-orbital cortex during go/no-go task in children with ADHD. Nord. J. Psychiatry 75, 224-233. doi: 10.1080/08039488.2020.1864775

Bechara, A. (2005). Decision making, impulse control and loss of willpower to resist drugs: a neurocognitive perspective. Nat. Neurosci. 8, 1458-1463. doi: $10.1038 / \mathrm{nn} 1584$

Belmer, A., Beecher, K., Jacques, A., Patkar, O. L., Sicherre, F., and Bartlett, S. E. (2019). Axonal non-segregation of the vesicular glutamate transporter VGLUT3 within serotonergic projections in the mouse forebrain. Front. Cell. Neurosci. 13:193. doi: 10.3389/fncel.2019.00193

Berkman, E. T., Falk, E. B., and Lieberman, M. D. (2012). Interactive effects of three core goal pursuit processes on brain control systems: goal maintenance, performance monitoring, and response inhibition. PLoS One 7:e40334. doi: 10.1371/journal.pone.0040334

Berridge, K. C., and Robinson, T. E. (2016). Liking, wanting, and the incentivesensitization theory of addiction. Am. Psychol. 71, 670-679. doi: 10.1037/ amp0000059

Billieux, J., Lagrange, G., Van der Linden, M., Lançon, C., Adida, M., and Jeanningros, R. (2012). Investigation of impulsivity in a sample of treatmentseeking pathological gamblers: a multidimensional perspective. Psychiatry Res. 198, 291-296. doi: 10.1016/j.psychres.2012.01.001

Bjork, J. M., Hommer, D. W., Grant, S. J., and Danube, C. (2004). Impulsivity in abstinent alcohol-dependent patients: relation to control subjects and type 1-/type 2-like traits. Alcohol 34, 133-150. doi: 10.1016/j.alcohol.2004.06.012

Blakemore, S. J., and Robbins, T. W. (2012). Decision-making in the adolescent brain. Nat. Neurosci. 15, 1184-1191. doi: 10.1038/nn.3177

Blokland, A., Sik, A., and Lieben, C. (2005). Evaluation of DOI, 8-OH-DPAT, eticlopride and amphetamine on impulsive responding in a reaction time task in rats. Behav. Pharmacol. 16, 93-100. doi: 10.1097/00008877-200503000-0 0004

Bocchio, M., Fucsina, G., Oikonomidis, L., McHugh, S. B., Bannerman, D. M., Sharp, T., et al. (2015). Increased serotonin transporter expression reduces fear and recruitment of parvalbumin interneurons of the amygdala. Neuropsychopharmacology 40, 3015-3026. doi: 10.1038/npp.2015. 157 
Bouton, M. E. (1993). Context, time, and memory retrieval in the interference paradigms of pavlovian learning. Psychol. Bull. 114, 80-99. doi: 10.1037/00332909.114.1.80

Bouton, M. E., Maren, S., and McNally, G. P. (2021). Behavioral and neurobiological mechanisms of pavlovian and instrumental extinction learning. Physiol. Rev. 101, 611-681. doi: 10.1152/physrev.00016.2020

Brevers, D., Cleeremans, A., Verbruggen, F., Bechara, A., Kornreich, C., Verbanck, P., et al. (2012). Impulsive action but not impulsive choice determines problem gambling severity. PLoS One 7:e50647. doi: 10.1371/journal.pone.0050647

Brodsky, M., Gibson, A. W., Smirnov, D., Nair, S. G., and Neumaier, J. F. (2016). Striatal 5-HT 6 receptors regulate cocaine reinforcement in a pathway-selective manner. Neuropsychopharmacology 41, 2377-2387. doi: 10.1038/npp.2016.45

Bromberg-Martin, E. S., Hikosaka, O., and Nakamura, K. (2010). Coding of task reward value in the dorsal raphe nucleus. J. Neurosci. 30, 6262-6272. doi: 10.1523/JNEUROSCI.0015-10.2010

Bryden, D. W., and Roesch, M. R. (2015). Executive control signals in orbitofrontal cortex during response inhibition. J. Neurosci. 35, 3903-3914. doi: 10.1523/ JNEUROSCI.3587-14.2015

Camchong, J., Endres, M., and Fein, G. (2014). Decision making, risky behavior, and alcoholism. Handb. Clin. Neurol. 125, 227-236. doi: 10.1016/B978-0-44462619-6.00014-8

Caras, M. L., MacKenzie, K., Rodwin, B., and Katz, D. B. (2008). Investigating the motivational mechanism of altered saline consumption following 5-HT1A manipulation. Behav. Neurosci. 122, 407-415. doi: 10.1037/0735-7044.122.2. 407

Casey, B. J., Jones, R. M., and Somerville, L. H. (2011). Braking and accelerating of the adolescent brain. J. Res. Adolesc. 21, 21-33. doi: 10.1111/j.1532-7795.2010. 00712.x

Castro, D. C., and Berridge, K. C. (2014). Opioid hedonic hotspot in nucleus accumbens shell: $\mathrm{Mu}$, delta, and kappa maps for enhancement of sweetness "liking" and "wanting.". J. Neurosci. 34, 4239-4250. doi: 10.1523/JNEUROSCI. 4458-13.2014

Chan, K. H., Jarrard, L. E., and Davidson, T. L. (2003). The effects of selective ibotenate lesions of the hippocampus on conditioned inhibition and extinction. Cogn. Affect. Behav. Neurosci. 3, 111-119. doi: 10.3758/CABN.3.2.111

Chen, C., Omiya, Y., and Yang, S. (2015). Dissociating contributions of ventral and dorsal striatum to reward learning. J. Neurophysiol. 114, 1364-1366. doi: 10.1152/jn.00873.2014

Chudasama, Y., Passetti, F., Rhodes, S. E. V., Lopian, D., Desai, A., and Robbins, T. W. (2003). Dissociable aspects of performance on the 5-choice serial reaction time task following lesions of the dorsal anterior cingulate, infralimbic and orbitofrontal cortex in the rat: differential effects on selectivity, impulsivity and compulsivity. Behav. Brain Res. 146, 105-119. doi: 10.1016/j.bbr.2003.09.020

Clark, L., Roiser, J. P., Cools, R., Rubinsztein, D. C., Sahakian, B. J., and Robbins, T. W. (2005). Stop signal response inhibition is not modulated by tryptophan depletion or the serotonin transporter polymorphism in healthy volunteers: implications for the 5-HT theory of impulsivity. Psychopharmacology 182, 570-578. doi: 10.1007/s00213-005-0104-6

Clarke, H. F., Walker, S. C., Dalley, J. W., Robbins, T. W., and Roberts, A. C. (2007). Cognitive inflexibility after prefrontal serotonin depletion is behaviorally and neurochemically specific. Cereb. Cortex 17, 18-27. doi: 10.1093/cercor/bhj120

Cohen, J. Y., Amoroso, M. W., and Uchida, N. (2015). Serotonergic neurons signal reward and punishment on multiple timescales. Elife 4:e06346. doi: 10.7554/ eLife.06346

Cools, R., Roberts, A. C., and Robbins, T. W. (2008). Serotoninergic regulation of emotional and behavioural control processes. Trends Cogn. Sci. 12, 31-40. doi: 10.1016/j.tics.2007.10.011

Corbit, L. H., and Janak, P. H. (2007). Inactivation of the lateral but not medial dorsal striatum eliminates the excitatory impact of pavlovian stimuli on instrumental responding. J. Neurosci. 27, 13977-13981. doi: 10.1523/ JNEUROSCI.4097-07.2007

Corbit, L. H., and Janak, P. H. (2010). Posterior dorsomedial striatum is critical for both selective instrumental and Pavlovian reward learning. Eur. J. Neurosci. 31, 1312-1321. doi: 10.1111/j.1460-9568.2010.07153.x

Crockett, M. J., Clark, L., and Robbins, T. W. (2009). Reconciling the role of serotonin in behavioral inhibition and aversion: acute tryptophan depletion abolishes punishment-induced inhibition in humans. J. Neurosci. 29, 11993 11999. doi: 10.1523/JNEUROSCI.2513-09.2009
Crockett, M. J., Clark, L., Apergis-Schoute, A. M., Morein-Zamir, S., and Robbins, T. W. (2012). Serotonin modulates the effects of pavlovian aversive predictions on response vigor. Neuropsychopharmacology 37, 2244-2252. doi: 10.1038/npp. 2012.75

da Cunha-Bang, S., Hjordt, L. V., Dam, V. H., Stenbæk, D. S., Sestoft, D., and Knudsen, G. M. (2017). Anterior cingulate serotonin 1B receptor binding is associated with emotional response inhibition. J. Psychiatric Res. 92, 199-204. doi: 10.1016/j.jpsychires.2017.05.003

da Silva, A. A. M., Oliveira, M. M., Cavalcante, T. C. F., do Amaral Almeida, L. C., Cruz, P. L. M., and de Souza, S. L. (2018). Undernutrition during pregnancy and lactation increases the number of fos-cells in the reward system in response to a 5-HT6 receptor agonist in male adolescent rats. Int. J. Food Sci. Nutr. 69, 488-493. doi: 10.1080/09637486.2017.1382455

Dalley, J. W., and Robbins, T. W. (2017). Fractionating impulsivity: neuropsychiatric implications. Nat. Rev. Neurosci. 18, 158-171. doi: $10.1038 / \mathrm{nrn} .2017 .8$

Dalley, J. W., Everitt, B. J., and Robbins, T. W. (2011). Impulsivity, compulsivity, and top-down cognitive control. Neuron 69, 680-694. doi: 10.1016/j.neuron. 2011.01.020

Dalley, J. W., Theobald, D. E., Pereira, E. A. C., Li, P. M. M. C., and Robbins, T. W. (2002). Specific abnormalities in serotonin release in the prefrontal cortex of isolation-reared rats measured during behavioural performance of a task assessing visuospatial attention and impulsivity. Psychopharmacology 164, 329-340. doi: 10.1007/s00213-002-1215-y

Darna, M., Chow, J. J., Yates, J. R., Charnigo, R. J., Beckmann, J. S., Bardo, M. T., et al. (2015). Role of serotonin transporter function in rat orbitofrontal cortex in impulsive choice. Behav. Brain Res. 293, 134-142. doi: 10.1016/j.bbr.2015.07. 025

Day, J. J., and Carelli, R. M. (2007). The nucleus accumbens and pavlovian reward learning. Neuroscientist 13, 148-159. doi: 10.1177/1073858406295854

Dayan, P., and Huys, Q. J. M. (2008). Serotonin, inhibition, and negative mood. PLoS Comput. Biol. 4:e4. doi: 10.1371/journal.pcbi.0040004

de Bruin, N. M. W. J., McCreary, A. C., van Loevezijn, A., de Vries, T. J., Venhorst, J., van Drimmelen, M., et al. (2013). A novel highly selective 5-HT6 receptor antagonist attenuates ethanol and nicotine seeking but does not affect inhibitory response control in Wistar rats. Behav. Brain Res. 236, 157-165. doi: 10.1016/j. bbr.2012.08.048

Dembrow, N., and Johnston, D. (2014). Subcircuit-specific neuromodulation in the prefrontal cortex. Front. Neural Circuits 8:54. doi: 10.3389/fncir.2014.00054

Desrochers, S. S., Lesko, E. K., Magalong, V. M., Balsam, P. D., and Nautiyal, K. M. (2021). A role for reward valuation in the serotonergic modulation of impulsivity. Psychopharmacology 238, 3293-3309. doi: 10.1007/s00213-02105944-2

Diergaarde, L., Pattij, T., Nawijn, L., Schoffelmeer, A. N. M., and De Vries, T. J. (2009). Trait impulsivity predicts escalation of sucrose seeking and hypersensitivity to sucrose-associated stimuli. Behav. Neurosci. 123, 794-803. doi: $10.1037 / \mathrm{a} 0016504$

Dölen, G., Darvishzadeh, A., Huang, K. W., and Malenka, R. C. (2013). Social reward requires coordinated activity of nucleus accumbens oxytocin and serotonin. Nature 501, 179-184. doi: 10.1038/nature12518

Doly, S., Bertran-Gonzalez, J., Callebert, J., Bruneau, A., Banas, S. M., Belmer, A., et al. (2009). Role of serotonin via 5-HT2B receptors in the reinforcing effects of MDMA in mice. PLoS One 4:e7952. doi: 10.1371/journal.pone.000 7952

Dong, C., Ly, C., Dunlap, L. E., Vargas, M. V., Sun, J., Hwang, I. W., et al. (2021). Psychedelic-inspired drug discovery using an engineered biosensor. Cell 184, 2779-2792.e18. doi: 10.1016/j.cell.2021.03.043

Donnelly, N. A., Holtzman, T., Rich, P. D., Nevado-Holgado, A. J., Fernando, A. B. P., Van Dijck, G., et al. (2014). Oscillatory activity in the medial prefrontal cortex and nucleus accumbens correlates with impulsivity and reward outcome. PLoS One 9:e111300. doi: 10.1371/journal.pone.0111300

Dreyfuss, M., Caudle, K., Drysdale, A. T., Johnston, N. E., Cohen, A. O., Somerville, L. H., et al. (2014). Teens impulsively react rather than retreat from threat. Dev. Neurosci. 36, 220-227. doi: 10.1159/000357755

Eagle, D. M., Baunez, C., Hutcheson, D. M., Lehmann, O., Shah, A. P., and Robbins, T. W. (2008b). Stop-signal reaction-time task performance: role of prefrontal cortex and subthalamic nucleus. Cereb. Cortex 18, 178-188. doi: 10.1093/cercor/ bhm044 
Eagle, D. M., Bari, A., and Robbins, T. W. (2008a). The neuropsychopharmacology of action inhibition: cross-species translation of the stop-signal and go/no-go tasks. Psychopharmacology 199, 439-456. doi: 10.1007/s00213-008-1127-6

Eagle, D. M., Lehmann, O., Theobald, D. E. H., Pena, Y., Zakaria, R., Ghosh, R., et al. (2009). Serotonin depletion impairs waiting but not stop-signal reaction time in rats: Implications for theories of the role of 5-HT in behavioral inhibition. Neuropsychopharmacology 34, 1311-1321. doi: 10.1038/npp.2008. 202

Ellingson, J. M., Verges, A., Littlefield, A. K., Martin, N. G., and Slutske, W. S. (2013). Are bottom-up and top-down traits in dual-systems models of risky behavior genetically distinct? Behav. Genet. 3, 480-490. doi: 10.1007/s10519013-9615-9

Ersche, K. D., Turton, A. J., Chamberlain, S. R., Müller, U., Bullmore, E. T., and Robbins, T. W. (2012). Cognitive dysfunction and anxious-impulsive personality traits are endophenotypes for drug dependence. Am. J. Psychiatry 169, 926-936. doi: 10.1176/appi.ajp.2012.11091421

Feja, M., Hayn, L., and Koch, M. (2014). Nucleus accumbens core and shell inactivation differentially affects impulsive behaviours in rats. Prog. Neuro Psychopharmacol. Biol. Psychiatry 54, 31-42. doi: 10.1016/j.pnpbp.2014.04.012

Ferguson, S. M., Mitchell, E. S., and Neumaier, J. F. (2008). Increased expression of 5-HT6 receptors in the nucleus accumbens blocks the rewarding but not psychomotor activating properties of cocaine. Biol. Psychiatry 63, 207-213. doi: 10.1016/j.biopsych.2007.02.018

Fillmore, M. T., and Rush, C. R. (2002). Impaired inhibitory control of behavior in chronic cocaine users. Drug Alcohol Depend. 66, 265-273. doi: 10.1016/S03768716(01)00206-X

Flagel, S. B., Clark, J. J., Robinson, T. E., Mayo, L., Czuj, A., Willuhn, I., et al. (2011). A selective role for dopamine in stimulus-reward learning. Nature 469, 53-57. doi: 10.1038/nature09588

Flagel, S. B., Robinson, T. E., Clark, J. J., Clinton, S. M., Watson, S. J., Seeman, P., et al. (2010). An animal model of genetic vulnerability to behavioral disinhibition and responsiveness to reward-related cues: implications for addiction. Neuropsychopharmacology 35, 388-400. doi: 10.1038/npp.2009.142

Fletcher, P. J. (1995). Effects of combined or separate 5,7-dihydroxytryptamine lesions of the dorsal and median raphe nuclei on responding maintained by a DRL 20s schedule of food reinforcement. Brain Res. 675, 45-54. doi: 10.1016/ 0006-8993(95)00037-Q

Fletcher, P. J., and Higgins, G. A. (1997). Differential effects of ondansetron and $\alpha-$ flupenthixol on responding for conditioned reward. Psychopharmacology 134, 64-72. doi: 10.1007/s002130050426

Fletcher, P. J., Azampanah, A., and Korth, K. M. (2002). Activation of 5HT1B receptors in the nucleus accumbens reduces self-administration of amphetamine on a progressive ratio schedule. Pharmacol. Biochem. Behav. 71, 717-725. doi: 10.1016/S0091-3057(01)00717-1

Fletcher, P. J., Chambers, J. W., Rizos, Z., and Chintoh, A. F. (2009). Effects of 5HT depletion in the frontal cortex or nucleus accumbens on response inhibition measured in the 5-choice serial reaction time test and on a DRL schedule. Behav. Brain Res. 201, 88-98. doi: 10.1016/j.bbr.2009.01.036

Fletcher, P. J., Ming, Z. H., and Higgins, G. A. (1993). Conditioned place preference induced by microinjection of 8-OH-DPAT into the dorsal or median raphe nucleus. Psychopharmacology 113, 31-36. doi: 10.1007/BF02244330

Fletcher, P. J., Soko, A. D., and Higgins, G. A. (2013). Impulsive action in the 5 -choice serial reaction time test in 5-HT(2)c receptor null mutant mice. Psychopharmacology (Berl) 226, 561-570. doi: 10.1007/s00213-012-2929-0

Fletcher, P. J., Tampakeras, M., and Yeomans, J. S. (1995). Median raphe injections of 8-OH-DPAT lower frequency thresholds for lateral hypothalamic selfstimulation. Pharmacol. Biochem. Behav. 52, 65-71. doi: 10.1016/0091-3057(94) 00441-K

Fletcher, P. J., Tampakeras, M., Sinyard, J., and Higgins, G. A. (2007). Opposing effects of $5-\mathrm{HT}(2 \mathrm{~A})$ and $5-\mathrm{HT}(2 \mathrm{C})$ receptor antagonists in the rat and mouse on premature responding in the five-choice serial reaction time test. Psychopharmacology (Berl) 195, 223-234. doi: 10.1007/s00213-007-0891-z

Fletcher, P. J., Zeeb, F. D., Browne, C. J., Higgins, G. A., and Soko, A. D. (2017). Effects of 5-HT1A, 5-HT2A and 5-HT2C receptor agonists and antagonists on responding for a conditioned reinforcer and its enhancement by methylphenidate. Psychopharmacology 234, 889-902. doi: 10.1007/s00213017-4529-5
Flores-Dourojeanni, J. P., Van Rijt, C., Van Den Munkhof, M. H., Boekhoudt, L., Luijendijk, M. C. M., Vanderschuren, L. J. M. J., et al. (2021). Temporally specific roles of ventral tegmental area projections to the nucleus accumbens and prefrontal cortex in attention and impulse control. J. Neurosci. 41, 42934304. doi: 10.1523/JNEUROSCI.0477-20.2020

Fonseca, M. S., Murakami, M., and Mainen, Z. F. (2015). Activation of dorsal raphe serotonergic neurons promotes waiting but is not reinforcing. Curr. Biol. 25, 306-315. doi: 10.1016/j.cub.2014.12.002

Fontaine, H. M., Silva, P. R., Neiswanger, C., Tran, R., Abraham, A. D., Land, B. B., et al. (2021). Stress decreases serotonin tone in the nucleus accumbens in male mice to promote aversion and potentiate cocaine preference via decreased stimulation of 5-HT1B receptors. Neuropsychopharmacology doi: 10 . 1038/s41386-021-01178-0 [Epub ahead of print].

Frick, L. R., Bernardez-Vidal, M., Hocht, C., Zanutto, B. S., and Rapanelli, M. (2015). Dual role of serotonin in the acquisition and extinction of reward-driven learning: involvement of 5-HT1A, 5-HT2A and 5-HT3 receptors. Behav. Brain Res. 277, 193-203. doi: 10.1016/j.bbr.2014.06.025

Furay, A. R., Neumaier, J. F., Mullenix, A. T., Kaiyala, K. K., Sandygren, N. K., and Hoplight, B. J. (2011). Overexpression of 5-HT(1B) mRNA in nucleus accumbens shell projection neurons differentially affects microarchitecture of initiation and maintenance of ethanol consumption. Alcohol 45, 19-32. doi: 10.1016/j.alcohol.2010.07.010

Geurts, D. E. M., Huys, Q. J. M., den Ouden, H. E. M., and Cools, R. (2013). Serotonin and aversive pavlovian control of instrumental behavior in humans. J. Neurosci. 33, 18932-18939. doi: 10.1523/JNEUROSCI.2749-13.2013

Goldman, D., Bevilacqua, L., Doly, S., Kaprio, J., Yuan, Q., Tikkanen, R., et al. (2010). A population-specific HTR2B stop codon predisposes to severe impulsivity. Nature 468, 1061-1068. doi: 10.1038/nature09629

Graeff, F. G., Viana, M. B., and Mora, P. O. (1997). Dual role of 5-HT in defense and anxiety. Neurosci. Biobehav. Rev. 21, 791-799. doi: 10.1016/S0149-7634(96) 00059-0

Grandjean, A., Suarez, I., Diaz, E., Spieser, L., Burle, B., Blaye, A., et al. (2021). Stronger impulse capture and impaired inhibition of prepotent action in children with ADHD performing a Simon task: an electromyographic study. Neuropsychology 35, 399-410. doi: 10.1037/neu0000668

Grant, R. I., Doncheck, E. M., Vollmer, K. M., Winston, K. T., Romanova, E. V., Siegler, P. N., et al. (2021). Specialized coding patterns among dorsomedial prefrontal neuronal ensembles predict conditioned reward seeking (Running title: Neuronal ensembles in prefrontal cortex). eLife 10:e65764. doi: 10.7554/ eLife. 65764

Groft, M. L., Normann, M. C., Nicklas, P. R., Jagielo-Miller, J. E., and McLaughlin, P. J. (2019). Biphasic effects of 5-HT1A agonism on impulsive responding are dissociable from effects on anxiety in the variable consecutive number task. Naunyn-Schmiedebergs Arch. Pharmacol. 392, 1455-1464. doi: 10.1007/s00210019-01684-5

Harrison, A. A., Everitt, B. J., and Robbins, T. W. (1997). Central 5-HT depletion enhances impulsive responding without affecting the accuracy of attentional performance: interactions with dopaminergic mechanisms. Psychopharmacology 133, 329-342. doi: 10.1007/s002130050410

Harrison, A. A., Everitt, B. J., and Robbins, T. W. (1999a). Central serotonin depletion impairs both the acquisition and performance of a symmetrically reinforced go/no-go conditional visual discrimination. Behav. Brain Res. 100, 99-112. doi: 10.1016/S0166-4328(98)00117-X

Harrison, A. A., Parsons, L. H., Koob, G. F., and Markou, A. (1999b). RU 24969, a $5-\mathrm{HT}(1 \mathrm{~A} / 1 \mathrm{~B})$ agonist, elevates brain stimulation reward thresholds: an effect reversed by GR 127935, a 5-HT(1B/1D) antagonist. Psychopharmacology 141, 242-250. doi: 10.1007/s002130050831

Hart, G., Bradfield, L. A., Fok, S. Y., Chieng, B., and Balleine, B. W. (2018). The bilateral prefronto-striatal pathway is necessary for learning new goal-directed actions. Curr. Biol. 28, 2218-2229.e7. doi: 10.1016/j.cub.2018.05.028

Hayashi, K., Nakao, K., and Nakamura, K. (2015). Appetitive and aversive information coding in the primate dorsal raphé nucleus. J. Neurosci. 35, 61956208. doi: 10.1523/JNEUROSCI.2860-14.2015

He, Z., Cassaday, H. J., Howard, R. C., Khalifa, N., and Bonardi, C. (2011). Impaired pavlovian conditioned inhibition in offenders with personality disorders. Q. J. Exp. Psychol. 64, 2334-2351. doi: 10.1080/17470218.2011.61 6933 
Hester, R., Fassbender, C., and Garavan, H. (2004). Individual differences in error processing: a review and reanalysis of three event-related fMRI studies using the GO/NOGO task. Cereb. Cortex 14, 986-994. doi: 10.1093/cercor/bhh059

Higgins, G. A., Joharchi, N., Nguyen, P., and Sellers, E. M. (1992). Effect of the 5-HT3 receptor antagonists, MDL72222 and ondansetron on morphine place conditioning. Psychopharmacology 106, 315-320. doi: 10.1007/BF02245411

Hodgins, D. C., and Holub, A. (2015). Components of impulsivity in gambling disorder. Int. J. Ment. Health Addict. 13, 699-711. doi: 10.1007/s11469-0159572-z

Holland, P. C. (1989). Transfer of negative occasion setting and conditioned inhibition across conditioned and unconditioned stimuli. J. Exp. Psychol. 15, 311-328. doi: 10.1037/0097-7403.15.4.311

Holmes, A. J., Bogdan, R., and Pizzagalli, D. A. (2010). Serotonin transporter genotype and action monitoring dysfunction: A possible substrate underlying increased vulnerability to depression. Neuropsychopharmacology 35, 11861197. doi: 10.1038/npp.2009.223

Homberg, J. R., Olivier, J. D. A., Smits, B. M. G., Mul, J. D., Mudde, J., Verheul, M., et al. (2007). Characterization of the serotonin transporter knockout rat: a selective change in the functioning of the serotonergic system. Neuroscience 146, 1662-1676. doi: 10.1016/j.neuroscience.2007.03.030

Hong, J. S., Kim, S. M., Bae, S., and Han, D. H. (2018). Impulsive internet game play is associated with increased functional connectivity between the default mode and salience networks in depressed patients with short allele of serotonin transporter gene. Front. Psychiatry 9:125. doi: 10.3389/fpsyt.2018.00125

Howard, J. D., Gottfried, J. A., Tobler, P. N., and Kahnt, T. (2015). Identity-specific coding of future rewards in the human orbitofrontal cortex. Proc. Natl. Acad. Sci. U.S.A. 112, 5195-5200. doi: 10.1073/pnas.1503550112

Huang, K. W., Ochandarena, N. E., Philson, A. C., Hyun, M., Birnbaum, J. E., Cicconet, M., et al. (2019). Molecular and anatomical organization of the dorsal raphe nucleus. eLife 8:e46464. doi: 10.7554/eLife.46464

Ioannidis, K., Hook, R., Wickham, K., Grant, J. E., and Chamberlain, S. R. (2019). Impulsivity in Gambling Disorder and problem gambling: a metaanalysis. Neuropsychopharmacology 44, 1354-1361. doi: 10.1038/s41386-019-0 393-9

Jentsch, J. D., Ashenhurst, J. R., Cervantes, M. C., Groman, S. M., James, A. S., and Pennington, Z. T. (2014). Dissecting impulsivity and its relationships to drug addictions. Ann. N. Y. Acad. Sci. 1327, 1-26. doi: 10.1111/nyas.12388

Jiménez-Murcia, S., Fernández-Aranda, F., Mestre-Bach, G., Granero, R., Tárrega, S., Torrubia, R., et al. (2017). Exploring the relationship between reward and punishment sensitivity and gambling disorder in a clinical sample: a path modeling analysis. J. Gambl. Stud. 33, 579-597. doi: 10.1007/s10899-016-96319

Jolly, D. C., Richards, J. B., and Seiden, L. S. (1999). Serotonergic mediation of DRL 72s behavior: Receptor subtype involvement in a behavioral screen for antidepressant drugs. Biol. Psychiatry 45, 1151-1162. doi: 10.1016/S00063223(98)00014-6

Kampov-Polevoy, A. B., Garbutt, J. C., and Khalitov, E. (2003). Family history of alcoholism and response to sweets. Alcoholism 27, 1743-1749. doi: 10.1097/01. ALC.0000093739.05809.DD

Kampov-Polevoy, A. B., Tsoi, M. V., Zvartau, E. E., Neznanov, N. G., and Khalitov, E. (2001). Sweet liking and family history of alcoholism in hospitalized alcoholic and non-alcoholic patients. Alcohol Alcohol. 36, 165-170. doi: 10.1093/alcalc/ 36.2.165

Kanen, J. W., Apergis-Schoute, A. M., Yellowlees, R., Arntz, F. E., van der Flier, F. E., Price, A., et al. (2021). Serotonin depletion impairs both Pavlovian and instrumental reversal learning in healthy humans. Mol. Psychiatry doi: 10.1038/ s41380-021-01240-9 [Epub ahead of print].

Kelley, S. P., and Hodge, C. W. (2003). The 5-HT3 antagonist Y-25130 blocks cocaine-induced lowering of ICSS reward thresholds in the rat. Pharmacol. Biochem. Behav. 74, 297-302. doi: 10.1016/S0091-3057(02)00985-1

Kim, J., Jung, A. H., Byun, J., Jo, S., and Jung, M. W. (2009). Inactivation of medial prefrontal cortex impairs time interval discrimination in rats. Front. Behav. Neurosci. 3:38. doi: 10.3389/neuro.08.038.2009

Klein, A. B., Ultved, L., Adamsen, D., Santini, M. A., Tobeña, A., Fernandez-Teruel, A., et al. (2014). 5-HT2A and mGlu2 receptor binding levels are related to differences in impulsive behavior in the Roman Low- (RLA) and High- (RHA) avoidance rat strains. Neuroscience 263, 36-45. doi: 10.1016/j.neuroscience. 2013.12.063
Korte, S. M., Prins, J., Van den Bergh, F. S., Oosting, R. S., Dupree, R., KorteBouws, G. A. H., et al. (2017). The 5-HT1A/1B-receptor agonist eltoprazine increases both catecholamine release in the prefrontal cortex and dopamine release in the nucleus accumbens and decreases motivation for reward and "waiting” impulsivity, but increases "stopping" impulsivity. Eur. J. Pharmacol. 794, 257-269. doi: 10.1016/j.ejphar.2016.11.024

Koskinen, T., Ruotsalainen, S., Puumala, T., Lappalainen, R., Koivisto, E., Männistö, P. T., et al. (2000b). Activation of 5-HT(2A) receptors impairs response control of rats in a five-choice serial reaction time task. Neuropharmacology 39, 471-481. doi: 10.1016/S0028-3908(99)00159-8

Koskinen, T., Ruotsalainen, S., and Sirviö, J. (2000a). The 5-HT2 receptor activation enhances impulsive responding without increasing motor activity in rats. Pharmacol. Biochem. Behav. 66, 729-738. doi: 10.1016/S0091-3057(00) 00241-0

Kozak, K., Lucatch, A. M., Lowe, D. J. E., Balodis, I. M., MacKillop, J., and George, T. P. (2019). The neurobiology of impulsivity and substance use disorders: implications for treatment. Ann. N. Y. Acad. Sci. 1451, 71-91. doi: 10.1111/nyas. 13977

Kumar, R., Kumar, K. J., and Benegal, V. (2018). Trait impulsivity in alcoholnaïve offspring at high risk for alcoholism. Indian J. Psychol. Med. 40, 547-555. doi: 10.4103/IJPSYM.IJPSYM_92_18

Leong, J. K., MacNiven, K. H., Samanez-Larkin, G. R., and Knutson, B. (2018). Distinct neural circuits support incentivized inhibition. NeuroImage 178, 435444. doi: 10.1016/j.neuroimage.2018.05.055

Li, B., Nguyen, T. P., Ma, C., and Dan, Y. (2020). Inhibition of impulsive action by projection-defined prefrontal pyramidal neurons. Proc. Natl. Acad. Sci. U.S.A. 117, 17278-17287. doi: 10.1073/pnas.2000523117

Li, Y., Zhong, W., Wang, D., Feng, Q., Liu, Z., Zhou, J., et al. (2016). Serotonin neurons in the dorsal raphe nucleus encode reward signals. Nat. Commun. 7:10503. doi: 10.1038/ncomms10503

Lichtenberg, N. T., Sepe-Forrest, L., Pennington, Z. T., Lamparelli, A. C., Greenfield, V. Y., and Wassum, K. M. (2021). The medial orbitofrontal cortexbasolateral amygdala circuit regulates the influence of reward cues on adaptive behavior and choice. J. Neurosci. 41, 7267-7277. doi: 10.1523/JNEUROSCI. 0901-21.2021

Lister, S., Pearce, J. M., Butcher, S. P., Collard, K. J., and Foster, G. A. (1996). Acquisition of conditioned inhibition in rats is impaired by ablation of serotoninergic pathways. Eur. J. Neurosci. 8, 415-423. doi: 10.1111/j.1460-9568. 1996.tb01224.x

MacKillop, J., Weafer, J., Gray, J. C., Oshri, A., Palmer, A., and de Wit, H. (2016). The latent structure of impulsivity: impulsive choice, impulsive action, and impulsive personality traits. Psychopharmacology 233, 3361-3370. doi: 10.1007/ s00213-016-4372-0

MacLeod, J. E., and Bucci, D. J. (2010). Contributions of the subregions of the medial prefrontal cortex to negative occasion setting. Behav. Neurosci. 124, 321-328. doi: 10.1037/a0019344

Malvaez, M., Shieh, C., Murphy, M. D., Greenfield, V. Y., and Wassum, K. M. (2019). Distinct cortical-amygdala projections drive reward value encoding and retrieval. Nat. Neurosci. 22, 762-769. doi: 10.1038/s41593-019-0374-7

Man, M. S., Mikheenko, Y., Braesicke, K., Cockcroft, G., and Roberts, A. C. (2012). Serotonin at the level of the amygdala and orbitofrontal cortex modulates distinct aspects of positive emotion in primates. Int. J. Neuropsychopharmacol. 15, 91-105. doi: 10.1017/S1461145711000587

Masaki, D., Yokoyama, C., Kinoshita, S., Tsuchida, H., Nakatomi, Y., Yoshimoto, K., et al. (2006). Relationship between limbic and cortical 5HT neurotransmission and acquisition and reversal learning in a go/no-go task in rats. Psychopharmacology 189, 249-258. doi: 10.1007/s00213-0060559-0

Matsui, A., and Alvarez, V. A. (2018). Cocaine inhibition of synaptic transmission in the ventral pallidum is pathway-specific and mediated by serotonin. Cell Rep. 23, 3852-3863. doi: 10.1016/j.celrep.2018.05.076

Mechelmans, D. J., Strelchuk, D., Doñamayor, N., Banca, P., Robbins, T. W., Baek, K., et al. (2017). Reward sensitivity and waiting impulsivity: shift towards reward valuation away from action control. Int. J. Neuropsychopharmacol. 20, 971-978. doi: 10.1093/ijnp/pyx072

Mestre-Bach, G., Steward, T., Granero, R., Fernández-Aranda, F., Mena-Moreno, T., Vintró-Alcaraz, C., et al. (2020). Dimensions of impulsivity in gambling disorder. Sci. Rep. 10:397. doi: 10.1038/s41598-019-57117-z 
Meyer, H. C., and Bucci, D. J. (2014). The contribution of medial prefrontal cortical regions to conditioned inhibition. Behav. Neurosci. 128, 644-653. doi: 10.1037/ bne 0000023

Meyer, H. C., and Bucci, D. J. (2016a). Age differences in appetitive Pavlovian conditioning and extinction in rats. Physiol. Behav. 167, 354-362. doi: 10.1016/ j.physbeh.2016.10.004

Meyer, H. C., and Bucci, D. J. (2016b). Imbalanced activity in the orbitofrontal cortex and nucleus accumbens impairs behavioral inhibition. Curr. Biol. 26, 2834-2839. doi: 10.1016/j.cub.2016.08.034

Meyer, H. C., and Bucci, D. J. (2017). Negative occasion setting in juvenile rats. Behav. Process. 137, 33-39. doi: 10.1016/j.beproc.2016.05.003

Millan, E. Z., and McNally, G. P. (2011). Accumbens shell AMPA receptors mediate expression of extinguished reward seeking through interactions with basolateral amygdala. Learn. Mem. 18, 414-421. doi: 10.1101/lm.2144411

Mitchell, E. S., Sexton, T., and Neumaier, J. F. (2007). Increased expression of 5HT6 receptors in the rat dorsomedial striatum impairs instrumental learning. Neuropsychopharmacology 32, 1520-1530. doi: 10.1038/sj.npp.1301284

Miyazaki, K. W., Miyazaki, K., and Doya, K. (2012). Activation of dorsal raphe serotonin neurons is necessary for waiting for delayed rewards. J. Neurosci. 32, 10451-10457. doi: 10.1523/JNEUROSCI.0915-12.2012

Miyazaki, K. W., Miyazaki, K., Tanaka, K. F., Yamanaka, A., Takahashi, A., Tabuchi, S., et al. (2014). Optogenetic activation of dorsal raphe serotonin neurons enhances patience for future rewards. Curr. Biol. 24, 2033-2040. doi: 10.1016/j. cub.2014.07.041

Miyazaki, K., Miyazaki, K. W., and Doya, K. (2011). Activation of dorsal raphe serotonin neurons underlies waiting for delayed rewards. J. Neurosci. 31, 469479. doi: 10.1523/JNEUROSCI.3714-10.2011

Miyazaki, K., Miyazaki, K. W., Sivori, G., Yamanaka, A., Tanaka, K. F., and Doya, K. (2020). Serotonergic projections to the orbitofrontal and medial prefrontal cortices differentially modulate waiting for future rewards. Sci. Adv. 6:eabc7246. doi: $10.1126 /$ sciadv.abc7246

Miyazaki, K., Miyazaki, K. W., Yamanaka, A., Tokuda, T., Tanaka, K. F., and Doya, K. (2018). Reward probability and timing uncertainty alter the effect of dorsal raphe serotonin neurons on patience. Nat. Commun. 9:2048. doi: 10.1038/s41467-018-04496-y

Mogenson, G. J., Swanson, L. W., and Wu, M. (1983). Neural projections from nucleus accumbens to globus pallidus, substantia innominata, and lateral preoptic-lateral hypothalamic area: an anatomical and electrophysiological investigation in the rat. J. Neurosci. 3, 189-202. doi: 10.1523/jneurosci.03-0100189.1983

Monterosso, J. R., Aron, A. R., Cordova, X., Xu, J., and London, E. D. (2005). Deficits in response inhibition associated with chronic methamphetamine abuse. Drug Alcohol Depend. 79, 273-277. doi: 10.1016/j.drugalcdep.2005.02. 002

Morales, I., and Berridge, K. C. (2020). 'Liking' and 'wanting' in eating and food reward: brain mechanisms and clinical implications. Physiol. Behav. 227:113152. doi: 10.1016/j.physbeh.2020.113152

Moreno, M., Cardona, D., Gómez, M. J., Sánchez-Santed, F., Tobña, A., FernándezTeruel, A., et al. (2010). Impulsivity characterization in the roman highand low-avoidance rat strains: behavioral and neurochemical differences. Neuropsychopharmacology 35, 1198-1208. doi: 10.1038/npp.2009.224

Morris, R. W., and Bouton, M. E. (2006). Effect of unconditioned stimulus magnitude on the emergence of conditioned responding. J. Exp. Psychol. 32, 371-385. doi: 10.1037/0097-7403.32.4.371

Murrough, J. W., Henry, S., Hu, J., Gallezot, J. D., Planeta-Wilson, B., Neumaier, J. F., et al. (2011). Reduced ventral striatal/ventral pallidal serotonin1B receptor binding potential in major depressive disorder. Psychopharmacology 213, 547553. doi: 10.1007/s00213-010-1881-0

Nakamura, K., Matsumoto, M., and Hikosaka, O. (2008). Reward-dependent modulation of neuronal activity in the primate dorsal raphe nucleus. J. Neurosci. 28, 5331-5343. doi: 10.1523/JNEUROSCI.0021-08.2008

Napier, T. C., and Istre, E. D. (2008). Methamphetamine-induced sensitization includes a functional upregulation of ventral pallidal 5-HT2A/2C receptors. Synapse 62, 14-21. doi: 10.1002/syn.20460

Narayanan, N. S., and Laubach, M. (2006). Top-down control of motor cortex ensembles by dorsomedial prefrontal cortex. Neuron 52, 921-931. doi: 10.1016/ j.neuron.2006.10.021
Narayanan, V., Heiming, R. S., Jansen, F., Lesting, J., Sachser, N., Pape, H. C., et al. (2011). Social defeat: impact on fear extinction and amygdala-prefrontal cortical theta synchrony in 5-HTT deficient mice. PLoS One 6:e22600. doi: 10.1371/journal.pone.0022600

Nautiyal, K. M., Tanaka, K. F., Barr, M. M., Tritschler, L., Le Dantec, Y., David, D. J., et al. (2015). Distinct circuits underlie the effects of 5-HT1B receptors on aggression and impulsivity. Neuron 86, 813-826. doi: 10.1016/j.neuron.2015.03. 041

Nautiyal, K. M., Wall, M. M., Wang, S., Magalong, V. M., Ahmari, S. E., Balsam, P. D., et al. (2017). Genetic and modeling approaches reveal distinct components of impulsive behavior. Neuropsychopharmacology 42, 1182-1191. doi: $10.1038 /$ npp. 2016.277

Neufang, S., Akhrif, A., Herrmann, C. G., Drepper, C., Homola, G. A., Nowak, J., et al. (2016). Serotonergic modulation of "waiting impulsivity" is mediated by the impulsivity phenotype in humans. Transl. Psychiatry 6:e940. doi: 10.1038/ tp. 2016.210

Neumaier, J. F., Vincow, E. S., Arvanitogiannis, A., Wise, R. A., and Carlezon, W. A. (2002). Elevated expression of 5-HT1B receptors in nucleus accumbens efferents sensitizes animals to cocaine. J. Neurosci. 22, 10856-10863. doi: 10. 1523/jneurosci.22-24-10856.2002

Nigg, J. T. (2001). Is ADHD a disinhibitory disorder? Psychol. Bull. 127, 571-598. doi: 10.1037/0033-2909.127.5.571

Nonkes, L. J. P., and Homberg, J. R. (2013). Perseverative instrumental and Pavlovian responding to conditioned stimuli in serotonin transporter knockout rats. Neurobiol. Learn. Mem. 100, 48-55. doi: 10.1016/j.nlm.2012.1 2.004

Nonkes, L. J. P., Tomson, K., Mærtin, A., Dederen, J., Roald Maes, J. H., and Homberg, J. (2010). Orbitofrontal cortex and amygdalar over-activity is associated with an inability to use the value of expected outcomes to guide behaviour in serotonin transporter knockout rats. Neurobiol. Learn. Mem. 94, 65-72. doi: 10.1016/j.nlm.2010.04.002

Nonkes, L. J. P., van de Vondervoort, I. I. G. M., and Homberg, J. R. (2014). The attribution of incentive salience to an appetitive conditioned cue is not affected by knockout of the serotonin transporter in rats. Behav. Brain Res. 259, 268-273. doi: 10.1016/j.bbr.2013.11.017

Nonkes, L. J. P., Van De Vondervoort, I. I. G. M., De Leeuw, M. J. C., Wijlaars, L. P., Maes, J. H. R., and Homberg, J. R. (2012). Serotonin transporter knockout rats show improved strategy set-shifting and reduced latent inhibition. Learn. Mem. 19, 190-193. doi: 10.1101/lm.025908.112

Odland, A. U., Sandahl, R., and Andreasen, J. T. (2021). Sequential reversal learning: a new touchscreen schedule for assessing cognitive flexibility in mice. Psychopharmacology 238, 383-397. doi: 10.1007/s00213-020-05687-6

Otis, J. M., Namboodiri, V. M. K., Matan, A. M., Voets, E. S., Mohorn, E. P., Kosyk, O., et al. (2017). Prefrontal cortex output circuits guide reward seeking through divergent cue encoding. Nature 543, 103-107. doi: 10.1038/nature21376

Otis, J. M., Zhu, M. H., Namboodiri, V. M. K., Cook, C. A., Kosyk, O., Matan, A. M., et al. (2019). Paraventricular thalamus projection neurons integrate cortical and hypothalamic signals for cue-reward processing. Neuron 103, 423-431.e4. doi: 10.1016/j.neuron.2019.05.018

Ottenheimer, D., Richard, J. M., and Janak, P. H. (2018). Ventral pallidum encodes relative reward value earlier and more robustly than nucleus accumbens. Nat. Commun. 9:4350. doi: 10.1038/s41467-018-06849-z

Pattij, T., Broersen, L. M., Van der Linde, J., Groenink, L., Van der Gugten, J., Maes, R. A. A., et al. (2003). Operant learning and differential-reinforcement-of-lowrate 36-s responding in 5-HT1A and 5-HT1B receptor knockout mice. Behav. Brain Res. 141, 137-145. doi: 10.1016/S0166-4328(02)00345-5

Pavlov, I. P. (1927). Conditioned Reflexes. London: Oxford University Press.

Pearce, J. M., and Hall, G. (1980). A model for Pavlovian learning: variations in the effectiveness of conditioned but not of unconditioned stimuli. Psychol. Rev. 87, 532-552. doi: 10.1037/0033-295x.87.6.532

Peciña, S. (2008). Opioid reward "liking" and "wanting" in the nucleus accumbens. Physiol. Behav. 94, 675-680. doi: 10.1016/j.physbeh.2008.04.006

Peciña, S., and Berridge, K. C. (2005). Hedonic hot spot in nucleus accumbens shell: where do $\mu$-Opioids cause increased hedonic impact of sweetness? J. Neurosci. 25, 11777-11786. doi: 10.1523/JNEUROSCI.2329-05.2005

Peciña, S., Smith, K. S., and Berridge, K. C. (2006). Hedonic hot spots in the brain. Neuroscientist 12, 500-511. doi: 10.1177/1073858406293154 
Pennanen, L., Van Der Hart, M., Yu, L., and Tecott, L. H. (2013). Impact of serotonin (5-HT) $2 \mathrm{C}$ receptors on executive control processes. Neuropsychopharmacology 38, 957-967. doi: 10.1038/npp.2012.258

Pereyra, A. E., Mininni, C. J., and Zanutto, B. S. (2021b). Serotonergic modulation of basolateral amygdala nucleus in the extinction of reward-driven learning: the role of 5-HT bioavailability and 5-HT1A receptor. Behav. Brain Res. 404:113161. doi: 10.1016/j.bbr.2021.113161

Pereyra, A. E., Mininni, C. J., and Zanutto, B. S. (2021a). Information capacity and robustness of encoding in the medial prefrontal cortex are modulated by the bioavailability of serotonin and the time elapsed from the cue during a reward-driven task. Sci. Rep. 11:13882. doi: 10.1038/s41598-021-93 313-6

Pisansky, M. T., Lefevre, E. M., Retzlaff, C. L., Trieu, B. H., Leipold, D. W., and Rothwell, P. E. (2019). Nucleus accumbens fast-spiking interneurons constrain impulsive action. Biol. Psychiatry 86, 836-847. doi: 10.1016/j.biopsych.2019.07. 002

Price, A. E., Sholler, D. J., Stutz, S. J., Anastasio, N. C., and Cunningham, K. A. (2019). Endogenous serotonin 5-HT2A and 5-HT2C receptors associate in the medial prefrontal cortex. ACS Chem. Neurosci. 10, 3241-3248. doi: 10.1021/ acschemneuro.8b00669

Puig, M. V., and Gulledge, A. T. (2011). Serotonin and prefrontal cortex function: neurons, networks, and circuits. Mol. Neurobiol. 44, 449-464. doi: 10.1007/ s12035-011-8214-0

Rainnie, D. G. (1999). Serotonergic modulation of neurotransmission in the rat basolateral amygdala. J. Neurophysiol. 82, 69-85. doi: 10.1152/jn.1999.82.1.69

Reavill, C., Hatcher, J. P., Lewis, V. A., Sanger, G. J., and Hagan, J. (1998). 5-HT4 receptor antagonism does not affect motor and reward mechanisms in the rat. Eur. J. Pharmacol. 357, 115-120. doi: 10.1016/s0014-2999(98)00564-0

Ren, J., Friedmann, D., Xiong, J., Liu, C. D., Ferguson, B. R., Weerakkody, T., et al. (2018). Anatomically defined and functionally distinct dorsal raphe serotonin sub-systems. Cell 175, 472-487 e20. doi: 10.1016/j.cell.2018.07.043

Ren, J., Isakova, A., Friedmann, D., Zeng, J., Grutzner, S. M., Pun, A., et al. (2019). Single-cell transcriptomes and whole-brain projections of serotonin neurons in the mouse dorsal and median raphe nuclei. eLife 8:e49424. doi: 10.7554/eLife. 49424

Rescorla, R. A., and Wagner, A. R. (1972). "A theory of pavlovian conditioning: variations in the effectiveness of reinforcement and nonreinforcement," in Classical Conditioning II: Current Research And Theory, eds A. H. Black and W. F. Prokosy (New York, NY: Appleton-Century-Crofts), 64-99. doi: 10.1037/ a0030892

Richard, J. M., Ambroggi, F., Janak, P. H., and Fields, H. L. (2016). Ventral pallidum neurons encode incentive value and promote cue-elicited instrumental actions. Neuron 90, 1165-1173. doi: 10.1016/j.neuron.2016.04.037

Robbins, T. W., and Everitt, B. J. (1996). Neurobehavioural mechanisms of reward and motivation. Curr. Opin. Neurobiol. 6, 228-236. doi: 10.1016/S09594388(96) $80077-8$

Robbins, T. W., Gillan, C. M., Smith, D. G., de Wit, S., and Ersche, K. D. (2012). Neurocognitive endophenotypes of impulsivity and compulsivity: towards dimensional psychiatry. Trends Cogn. Sci. 16, 81-91. doi: 10.1016/j.tics.2011. 11.009

Robertson, C. L., Ishibashi, K., Mandelkern, M. A., Brown, A. K., Ghahremani, D. G., Sabb, F., et al. (2015). Striatal D1- and D2-type dopamine receptors are linked to motor response inhibition in human subjects. J. Neurosci. 35, 5990-5997. doi: 10.1523/JNEUROSCI.4850-14.2015

Robinson, E. S. J., Dalley, J. W., Theobald, D. E. H., Glennon, J. C., Pezze, M. A., Murphy, E. R., et al. (2008). Opposing roles for 5-HT2A and 5-HT2C receptors in the nucleus accumbens on inhibitory response control in the 5-choice serial reaction time task. Neuropsychopharmacology 33, 2398-2406. doi: 10.1038/sj. npp.1301636

Rodd-Henricks, Z. A., McKinzie, D. L., Melendez, R. I., Berry, N., Murphy, J. M., and McBride, W. J. (2003). Effects of serotonin-3 receptor antagonists on the intracranial self-administration of ethanol within the ventral tegmental area of Wistar rats. Psychopharmacology 165, 252-259. doi: 10.1007/s00213-002-13002

Roger-Sánchez, C., Rodríguez-Arias, M., Miñarro, J., and Aguilar, M. A. (2013). Involvement of 5-hydroxytryptamine 5-HT3 serotonergic receptors in the acquisition and reinstatement of the conditioned place preference induced by MDMA. Eur. J. Pharmacol. 714, 132-141. doi: 10.1016/j.ejphar.2013.06.005
Rolls, E. T. (2004). Convergence of sensory systems in the orbitofrontal cortex in primates and brain design for emotion. Anat. Rec. Part A Discov. Mol. Cell. Evol. Biol. 281, 1212-1225. doi: 10.1002/ar.a.20126

Rompré, P. P., Injoyan, R., and Hagan, J. J. (1995). Effects of granisetron, a 5-HT3 receptor antagonist, on morphine-induced potentiation of brain stimulation reward. Eur. J. Pharmacol. 287, 263-269. doi: 10.1016/0014-2999(95)00497-1

Rubio, G., Jiménez, M., Rodríguez-Jiménez, R., Martínez, I., Ávila, C., Ferre, F., et al. (2008). The role of behavioral impulsivity in the development of alcohol dependence: a 4-year follow-up study. Alcoholism 32, 1681-1687. doi: 10.1111/ j.1530-0277.2008.00746.x

Rudebeck, P. H., Behrens, T. E., Kennerley, S. W., Baxter, M. G., Buckley, M. J., Walton, M. E., et al. (2008). Frontal cortex subregions play distinct roles in choices between actions and stimuli. J. Neurosci. 28, 13775-13785. doi: 10.1523/ JNEUROSCI.3541-08.2008

Schachar, R., and Logan, G. D. (1990). Impulsivity and inhibitory control in normal development and childhood psychopathology. Dev. Psychol. 26, 710-720. doi: 10.1037/0012-1649.26.5.710

Sengupta, A., Bocchio, M., Bannerman, D. M., Sharp, T., and Capogna, M. (2017). Control of amygdala circuits by 5 -HT neurons via 5 -HT and glutamate cotransmission. J. Neurosci. 37, 1785-1796. doi: 10.1523/JNEUROSCI.2238-16. 2016

Sesia, T., Bulthuis, V., Tan, S., Lim, L. W., Vlamings, R., Blokland, A., et al. (2010). Deep brain stimulation of the nucleus accumbens shell increases impulsive behavior and tissue levels of dopamine and serotonin. Exp. Neurol. 225, 302309. doi: 10.1016/j.expneurol.2010.06.022

Sesia, T., Temel, Y., Lim, L. W., Blokland, A., Steinbusch, H. W. M., and VisserVandewalle, V. (2008). Deep brain stimulation of the nucleus accumbens core and shell: opposite effects on impulsive action. Exp. Neurol. 214, 135-139. doi: 10.1016/j.expneurol.2008.07.015

Seymour, B., Daw, N. D., Roiser, J. P., Dayan, P., and Dolan, R. (2012). Serotonin selectively modulates reward value in human decision-making. J. Neurosci. 32, 5833-5842. doi: 10.1523/jneurosci.0053-12.2012

Shobe, J. L., Bakhurin, K. I., Claar, L. D., and Masmanidis, S. C. (2017). Selective modulation of orbitofrontal network activity during negative occasion setting. J. Neurosci. 37, 9415-9423. doi: 10.1523/JNEUROSCI.0572-17.2017

Sias, A. C., Morse, A. K., Wang, S., Greenfield, V. Y., Goodpaster, C. M., Wrenn, T. M., et al. (2021). A bidirectional corticoamygdala circuit for the encoding and retrieval of detailed reward memories. eLife 10:e68617. doi: 10.7554/eLife.68617

Silveira, M. M., Wittekindt, S. N., Mortazavi, L., Hathaway, B. A., and Winstanley, C. A. (2020). Investigating serotonergic contributions to cognitive effort allocation, attention, and impulsive action in female rats. J. Psychopharmacol. 34, 452-466. doi: 10.1177/0269881119896043

Smith, K. S., Tindell, A. J., Aldridge, J. W., and Berridge, K. C. (2009). Ventral pallidum roles in reward and motivation. Behav. Brain Res. 196, 155-167. doi: 10.1016/j.bbr.2008.09.038

Somerville, L. H., Hare, T., and Casey, B. J. (2011). Frontostriatal maturation predicts cognitive control failure to appetitive cues in adolescents. J. Cogn. Neurosci. 23, 2123-2134. doi: 10.1162/jocn.2010.21572

Somerville, L. H., Jones, R. M., and Casey, B. J. (2010). A time of change: behavioral and neural correlates of adolescent sensitivity to appetitive and aversive environmental cues. Brain Cogn. 72, 124-133. doi: 10.1016/j.bandc. 2009.07.003

Sosa, R., and dos Santos, C. V. (2019). Conditioned Inhibition and its Relationship to Impulsivity: empirical and Theoretical considerations. Psychol. Rec. 69, 315-332. doi: 10.1007/s40732-018-0325-9

Soubrié, P. (1986). Reconciling the role of central serotonin neurons in human and animal behavior. Behav. Brain Sci. 9, 319-335. doi: 10.1017/s0140525x00022871

Steinberg, L. (2010). A dual systems model of adolescent risk-taking. Dev. Psychobiol. 52, 216-224. doi: 10.1002/dev.20445

Stokes, M. G. (2015). "Activity-silent" working memory in prefrontal cortex: a dynamic coding framework. Trends Cogn. Sci. 19, 394-405. doi: 10.1016/j.tics. 2015.05.004

Strickland, J. C., and Johnson, M. W. (2021). Rejecting impulsivity as a psychological construct: a theoretical, empirical, and sociocultural argument. Psychol. Rev. 128, 336-361. doi: 10.1037/rev0000263

Svenningsson, P., Chergui, K., Rachleff, I., Flajolet, M., Zhang, X., El Yacoubi, M., et al. (2006). Alterations in 5-HT1B receptor function by p11 in depression-like states. Science 311, 77-80. doi: 10.1126/science.1117571 
Swick, D., Ashley, V., and Turken, A. U. (2008). Left inferior frontal gyrus is critical for response inhibition. BMC Neurosci. 9:102. doi: 10.1186/1471-2202-9-102

Sztainert, T., Wohl, M. J. A., McManus, J. F., and Stead, J. D. H. (2013). On being attracted to the possibility of a win: reward sensitivity (via gambling motives) undermines treatment seeking among pathological gamblers. J. Gambl. Stud. 30, 901-911. doi: 10.1007/s10899-013-9394-5

Talpos, J. C., Wilkinson, L. S., and Robbins, T. W. (2006). A comparison of multiple 5-HT receptors in two tasks measuring impulsivity. J. Psychopharmacol. 20, 47-58. doi: 10.1177/0269881105056639

Tanaka, S. C., Schweighofer, N., Asahi, S., Shishida, K., Okamoto, Y., Yamawaki, S., et al. (2007). Serotonin differentially regulates short- and long-term prediction of rewards in the ventral and dorsal striatum. PLoS One 2:e1333. doi: 10.1371/ journal.pone. 0001333

Tian, Z., Yamanaka, M., Bernabucci, M., Zhao, M. G., and Zhuo, M. (2017). Characterization of serotonin-induced inhibition of excitatory synaptic transmission in the anterior cingulate cortex. Mol. Brain 10:21. doi: 10.1186/ s13041-017-0303-1

Tiganj, Z., Jung, M. W., Kim, J., and Howard, M. W. (2017). Sequential firing codes for time in rodent medial prefrontal cortex. Cereb. Cortex 27, 5663-5671. doi: 10.1093/cercor/bhw336

Tindell, A. J., Smith, K. S., Peciña, S., Berridge, K. C., and Aldridge, J. W. (2006). Ventral pallidum firing codes hedonic reward: when a bad taste turns good. J. Neurophysiol. 96, 2399-2409. doi: 10.1152/jn.00576.2006

Todd, T. P., Vurbic, D., and Bouton, M. E. (2014). Behavioral and neurobiological mechanisms of extinction in Pavlovian and instrumental learning. Neurobiol. Learn. Mem. 108, 52-64. doi: 10.1016/j.nlm.2013.08.012

Trask, S., Thrailkill, E. A., and Bouton, M. E. (2017). Occasion setting, inhibition, and the contextual control of extinction in Pavlovian and instrumental (operant) learning. Behav.Process. 137, 64-72. doi: 10.1016/j.beproc.2016.10. 003

Treit, D., and Berridge, K. C. (1990). A comparison of benzodiazepine, serotonin, and dopamine agents in the taste-reactivity paradigm. Pharmacol. Biochem. Behav. 37, 451-456. doi: 10.1016/0091-3057(90)90011-6

Unger, E. K., Keller, J. P., Altermatt, M., Liang, R., Matsui, A., Dong, C., et al. (2020). Directed evolution of a selective and sensitive serotonin sensor via machine learning. Cell 183, 1986-2002.e26. doi: 10.1016/j.cell.2020.11.040

Valentini, V., Piras, G., De Luca, M. A., Perra, V., Bordi, F., Borsini, F., et al. (2013). Evidence for a role of a dopamine/5-HT6 receptor interaction in cocaine reinforcement. Neuropharmacology 65, 58-64. doi: 10.1016/j.neuropharm.2012. 08.025

Van Den Bos, R., Van Der Harst, J., Vijftigschild, N., Spruijt, B., Van Luijtelaar, G., and Maes, R. (2004). On the relationship between anticipatory behaviour in a Pavlovian paradigm and pavlovian-to-instrumental transfer in rats (Rattus norvegicus). Behav. Brain Res. 153, 397-408. doi: 10.1016/j.bbr.2003.12.017

van der Veen, B., Kapanaiah, S. K. T., Kilonzo, K., Steele-Perkins, P., Jendryka, M. M., Schulz, S., et al. (2021). Control of impulsivity by Gi-protein signalling in layer-5 pyramidal neurons of the anterior cingulate cortex. Commun. Biol. 4:662. doi: 10.1038/s42003-021-02188-w

Verharen, J. P. H., Van Den Heuvel, M. W., Luijendijk, M., Vanderschuren, L. J. M. J., and Adan, R. A. H. (2019). Corticolimbic mechanisms of behavioral inhibition under threat of punishment. J. Neurosci. 39, 4353-4364. doi: 10.1523/ JNEUROSCI.2814-18.2019

Wan, J., Peng, W., Li, X., Qian, T., Song, K., Zeng, J., et al. (2021). A genetically encoded sensor for measuring serotonin dynamics. Nat. Neurosci. 24, 746-752. doi: 10.1038/s41593-021-00823-7

Wang, H. L., Zhang, S., Qi, J., Wang, H., Cachope, R., Mejias-Aponte, C. A., et al. (2019). Dorsal raphe dual serotonin-glutamate neurons drive reward by establishing excitatory synapses on VTA mesoaccumbens dopamine neurons. Cell Rep. 26, 1128-1142.e7. doi: 10.1016/j.celrep.2019.0 1.014

Wang, Z., Yue, L., Cui, C., Liu, S., Wang, X., Li, Y., et al. (2019). Top-down control of the medial orbitofrontal cortex to nucleus accumbens core pathway in decisional impulsivity. Brain Struct. Funct. 224, 2437-2452. doi: 10.1007/ s00429-019-01913-w

Wardell, J. D., Quilty, L. C., Hendershot, C. S., and Bagby, R. M. (2015), Motivational pathways from reward sensitivity and punishment sensitivity to gambling frequency and gambling-related problems. Psychol. Addict. Behav. 29, 1022-1030. doi: 10.1037/adb0000066
Wassum, K. M., and Izquierdo, A. (2015). The basolateral amygdala in reward learning and addiction. Neurosci. Biobehav. Rev. 57, 271-283. doi: 10.1016/j. neubiorev.2015.08.017

Weafer, J., and De Wit, H. (2013). Inattention, impulsive action, and subjective response to d-amphetamine. Drug Alcohol Depend. 133, 127-133. doi: 10.1016/ j.drugalcdep.2013.05.021

Weafer, J., Crane, N. A., Gorka, S. M., Phan, K. L., and de Wit, H. (2019). Neural correlates of inhibition and reward are negatively associated. NeuroImage 196, 188-194. doi: 10.1016/j.neuroimage.2019.04.021

Weafer, J., Gorka, S. M., Hedeker, D., Dzemidzic, M., Kareken, D. A., Phan, K. L., et al. (2017). Associations between behavioral and neural correlates of inhibitory control and amphetamine reward sensitivity. Neuropsychopharmacology 42, 1905-1913. doi: 10.1038/npp.2017.61

Weafer, J., Mitchell, S. H., and de Wit, H. (2014). Recent translational findings on impulsivity in relation to drug abuse. Curr. Addict. Rep. 1, 289-300. doi: 10.1007/s40429-014-0035-6

Wellman, C. L., Izquierdo, A., Garrett, J. E., Martin, K. P., Carroll, J., Millstein, R., et al. (2007). Impaired stress-coping and fear extinction and abnormal corticolimbic morphology in serotonin transporter knock-out mice. J. Neurosci. 27, 684-691. doi: 10.1523/JNEUROSCI.4595-06.2007

Winstanley, C. A., Dalley, J. W., Theobald, D. E. H., and Robbins, T. W. (2003). Global 5-HT depletion attenuates the ability of amphetamine to decrease impulsive choice on a delay-discounting task in rats. Psychopharmacology 170, 320-331. doi: 10.1007/s00213-003-1546-3

Winstanley, C. A., Dalley, J. W., Theobald, D. E. H., and Robbins, T. W. (2004). Fractioning impulsivity: contrasting effects of central 5-HT depletion on different measures of impulsive behaviour. Neuropsychopharmacology 29, 1331-1343. doi: 10.1038/sj.npp.1300434

Winstanley, C. A., Olausson, P., Taylor, J. R., and Jentsch, J. D. (2010). Insight into the relationship between impulsivity and substance abuse from studies using animal models. Alcohol Clin. Exp. Res. 34, 1306-1318. doi: 10.1111/j.1530-0277. 2010.01215.x

Wischhof, L., Hollensteiner, K. J., and Koch, M. (2011). Impulsive behaviour in rats induced by intracortical DOI infusions is antagonized by co-administration of an mGlu2/3 receptor agonist. Behav. Pharmacol. 22, 805-813. doi: 10.1097/FBP. 0b013e32834d6279

Wise, C. D., Berger, B. D., and Stein, L. (1973). Evidence of -noradrenergic reward receptors and serotonergic punishment receptors in the rat brain. Biol. Psychiatry 6, 3-21.

Wogar, M. A., Bradshaw, C. M., and Szabadi, E. (1992). Impaired acquisition of temporal differentiation performance following lesions of the ascending 5hydroxytryptaminergic pathways. Psychopharmacology 107, 373-378. doi: 10. 1007/BF02245164

Worbe, Y., Savulich, G., Voon, V., Fernandez-Egea, E., and Robbins, T. W. (2014). Serotonin depletion induces "waiting impulsivity" on the human four-choice serial reaction time task: cross-species translational significance. Neuropsychopharmacology 39, 1519-1526. doi: 10.1038/npp.201 3.351

Wright, A. M., Zapata, A., Baumann, M. H., Elmore, J. S., Hoffman, A. F., and Lupica, C. R. (2017). Enduring loss of serotonergic control of orbitofrontal cortex function following contingent and noncontingent cocaine exposure. Cereb. Cortex 27, 5463-5476. doi: 10.1093/cercor/bhw312

Wright, A. M., Zapata, A., Hoffman, A. F., Necarsulmer, J. C., Coke, L. M., Svarcbahs, R., et al. (2021). Effects of withdrawal from cocaine selfadministration on rat orbitofrontal cortex parvalbumin neurons expressing cre recombinase: sex-dependent changes in neuronal function and unaltered serotonin signaling. ENeuro 8, doi: 10.1523/ENEURO.0017-21.2021

Wright, L., Lipszyc, J., Dupuis, A., Thayapararajah, S. W., and Schachar, R. (2014). Response inhibition and psychopathology: a meta-analysis of Go/No-Go task performance. J. Abnormal Psychol. 123, 429-439. doi: 10.1037/a0036295

Xu, M., Zhang, S. Y., Dan, Y., and Poo, M. M. (2014). Representation of interval timing by temporally scalable firing patterns in rat prefrontal cortex. Proc. Natl. Acad. Sci. U.S.A. 111, 480-485. doi: 10.1073/pnas.1321314111

Yoshimoto, K., McBride, W. J., Lumeng, L., and Li, T. K. (1992). Alcohol stimulates the release of dopamine and serotonin in the nucleus accumbens. Alcohol 9, 17-22. doi: 10.1016/0741-8329(92)90004-T

Yoshimoto, K., Watanabe, Y., Tanaka, M., and Kimura, M. (2012). Serotonin 2C receptors in the nucleus accumbens are involved in enhanced alcohol-drinking 
behavior. Eur. J. Neurosci. 35, 1368-1380. doi: 10.1111/j.1460-9568.2012.08 037.x

Zhong, W., Li, Y., Feng, Q., and Luo, M. (2017). Learning and stress shape the reward response patterns of serotonin neurons. J. Neurosci. 37, 8863-8875. doi: 10.1523/JNEUROSCI.1181-17.2017

Zhou, J., Jia, C., Feng, Q., Bao, J., and Luo, M. (2015). Prospective coding of dorsal raphe reward signals by the orbitofrontal cortex. J. Neurosci. 35, 2717-2730. doi: 10.1523/JNEUROSCI.4017-14.2015

Conflict of Interest: The authors declare that the research was conducted in the absence of any commercial or financial relationships that could be construed as a potential conflict of interest.
Publisher's Note: All claims expressed in this article are solely those of the authors and do not necessarily represent those of their affiliated organizations, or those of the publisher, the editors and the reviewers. Any product that may be evaluated in this article, or claim that may be made by its manufacturer, is not guaranteed or endorsed by the publisher.

Copyright (c) 2022 Desrochers, Spring and Nautiyal. This is an open-access article distributed under the terms of the Creative Commons Attribution License (CC BY). The use, distribution or reproduction in other forums is permitted, provided the original author(s) and the copyright owner(s) are credited and that the original publication in this journal is cited, in accordance with accepted academic practice. No use, distribution or reproduction is permitted which does not comply with these terms. 